\title{
Integration of H-2Z1, a Somatosensory Cortex-Expressed Transgene, Interferes with the Expression of the Satb1 and Tbc1d5 Flanking Genes and Affects the Differentiation of a Subset of Cortical Interneurons
}

\author{
Nicolas Narboux-Nême, ${ }^{1,2}$ Rosette Goïame, ${ }^{1}$ Marie-Geneviève Mattéi, ${ }^{3}$ Michel Cohen-Tannoudjii, ${ }^{4}$ and Marion Wassef ${ }^{1}$ \\ ${ }^{1}$ Institut de Biologie de l'Ecole Normale Supérieure, CNRS UMR 8197, Institut National de la Santé et de la Recherche Médicale Unité 1024 , F-75230 Paris \\ Cedex 05, France, ${ }^{2}$ Institut National de la Santé et de la Recherche Médicale, UMR-S 839, Université Pierre et Marie Curie, Institut du Fer à Moulin, F-75005 \\ Paris, France, ${ }^{3}$ Institut National de la Santé et de la Recherche Médicale UMR 910, Génétique Médicale et Génomique Fonctionnelle, F-13385 Marseille, \\ France, and ${ }^{4}$ Institut Pasteur, Unité de Génétique Fonctionnelle de la Souris, Département de Biologie du Développement, CNRS Unité de Recherche \\ Associée 2578, F-75015 Paris, France
}

$\mathrm{H}-2 \mathrm{Z1}$ is an enhancer trap transgenic mouse line in which the lacZ reporter delineates the somatosensory area of the cerebral cortex where it is expressed in a subset of layer IV neurons. In the search of somatosensory specific genes or regulatory sequences, we mapped the $\mathrm{H}-2 \mathrm{Z1}$ transgene insertion site to chromosome 17, 100 and $460 \mathrm{~kb}$ away from Tbc1d5 and Satb1 flanking genes. We show here that insertion of the H-2Z1 transgene results in three distinct outcomes. First, a genetic background-sensitive expression of lac $Z$ in several brain and body structures. While four genes in a $1 \mathrm{Mb}$ region around the insertion are expressed in the barrel cortex, $\mathrm{H}-2 \mathrm{Z1}$ expression resembles more that of its two direct neighbors. Moreover, H-2Z1 closely reports most of the body and brain expression sites of the Satb1 chromatin remodeling gene including tooth buds, thymic epithelium, pontine nuclei, fastigial cerebellar nuclei, and cerebral cortex. Second, the H-2Z1 transgene causes insertional mutagenesis of Tbc1d5 and Satb1, leading to a strong decrease in their expressions. Finally, insertion of $\mathrm{H}-2 \mathrm{Z} 1$ affects the differentiation of a subset of cortical GABAergic interneurons, a possible consequence of downregulation of Satb1 expression. Thus, the H-2Z1 "somatosensory" transgene is inserted in the regulatory landscape of two genes highly expressed in the developing somatosensory cortex and reports for a subdomain of their expression profiles. Together, our data suggest that regulation of $\mathrm{H}-2 \mathrm{Z1}$ expression results from local and remote genetic interactions.

\section{Introduction}

Cortical areas are functionally specialized domains of the cerebral cortex first identified on the basis of their distinct cytoarchitectures and axonal connections (Brodmann, 1909). Like in other regions of the neural tube (Briscoe et al., 2000), cerebral cortex patterning first involves the diffusion of signaling molecules produced by restricted patterning centers. In the cerebral cortex,

\footnotetext{
Received Dec. 7, 2011; revised March 19, 2012; accepted April 11, 2012.

Author contributions: M.C.-T. and M.W. designed research; N.N.-N., R.G., M.-G.M., M.C.-T., and M.W. performed research; N.N.-N., M.C.-T., and M.W. analyzed data; M.C.-T. and M.W. wrote the paper.

This work was supported by CNRS, École Normale Supérieure, and Institut Pasteur, and by Association pour la Recherche sur le Cancer grants (M.W.) and Pasteur-Weizmann grant (M.C.-T.). N.N.-N. was supported by fellowships from Ministère de l'Education Nationale, de la Recherche, et de la Technologie, and Fondation Pour La Recherche Médicale en France. We acknowledge the technical help of Sandrine Vandormael-Pournin. We thank Patricia Gaspar for continuous support and members of the Garel and Spassky groups for reagents and advice.

Correspondence should be addressed to either of the following: Michel Cohen-Tannoudji, Institut Pasteur, Unité de Génétique Fonctionnelle de la Souris, Département de Biologie du Développement, CNRS Unité de Recherche Associée 2578, 25 rue du Docteur Roux, F-75015 Paris, France, E-mail: m-cohen@pasteur.fr; or Marion Wassef, Institut de Biologie de l'Ecole Normale Supérieure, CNRS UMR 8197, Institut National de la Santé et de la Recherche Médicale Unité 1024, 46 rue d'Ulm, F-75230 Paris Cedex 05, France, E-mail: wassef@biologie.ens.fr.

N. Narboux-Nême's present address: Institut National de la Santé et de la Recherche Médicale Unité 830, Institut du Fer à Moulin, 17 rue du Fer à Moulin, F-75005 Paris, France.

DOI:10.1523/JNEUROSCI.6068-11.2012

Copyright $\odot 2012$ the authors $\quad 0270-6474 / 12 / 327287-14 \$ 15.00 / 0$
}

FGF, BMPs, Wnts, and Shh (Shimogori et al., 2004; Rash and Grove, 2006) control the graded expression of several transcription factors including Emx2, Coup-TF1, Pax6, and Sp8, which are expressed in distinct large overlapping domains (O'Leary et al., 2007) and control the size and positioning of cortical areas. Despite antagonistic properties, these transcription factors gradients do not resolve into sharp neuroepithelium progenitor domains as observed in the spinal cord, for example (Briscoe et al., 2000). Instead, they control the positioning of sharp boundaries of gene expression in the developing cortical layers (O'Leary et al., 2007). It is striking to observe that, while many genes show sharp upregulation or downregulation precisely in the somatosensory area (Paysan et al., 1997; Takeuchi et al., 2007; Joshi et al., 2008), no somatosensory-specific gene has yet been characterized. This suggests that areal identities, more specifically somatosensory area identity, do not rely on the expression of specific genes but rather on local combinations of layer-specific properties that are expressed more widely. In this context, the H-2Z1 (Cohen-Tannoudji et al., 1992, 1994) transgenic mouse line appears unique in that postnatally the transgene is specifically expressed in the somatosensory area.

$\mathrm{H}-2 \mathrm{Z1}$ is an enhancer trap transgenic mouse line maintained on a $\left(\mathrm{C} 57 \mathrm{BL} 6 \times \mathrm{CBA} \mathrm{F}_{1}\right.$ genetic background (noted C57/CBA 
hereafter) in which expression of the lac $Z$ reporter in the cerebral cortex is restricted to a subset of layer IV neurons and delineates precisely the somatosensory area (Cohen-Tannoudji et al., 1992, 1994). During development, the parietal cortex becomes competent for $\mathrm{H}-2 \mathrm{Z} 1$ expression at the time when areal identity is set in the developing cerebral cortex (Gitton et al., 1999a). Once turned on, shortly after birth, expression of the transgene is maintained lifelong (Gitton et al., 1999a). H-2Z1 therefore provides a unique cortical area and layer IV marker on a C57/CBA background. We speculated that the regulatory sequences driving expression of the transgene may belong to genes specifically expressed in the somatosensory area and located in the genome near the $\mathrm{H}-2 \mathrm{Z} 1$ insertion site. The initial aim of the present study was to take advantage of this unique transgenic line to try to identify a putative somatosensory-specific gene. Here, we describe the identification of several genes located in the vicinity of the $\mathrm{H}-2 \mathrm{Z} 1$ transgene insertion site and examine their expression profiles, how they relate to the somatosensory-specific expression of $\mathrm{H}-2 \mathrm{Z1}$, and how their expression is influenced by insertion of the $\mathrm{H}-\mathrm{Z} 1$ transgene.

\section{Materials and Methods}

Animals. The following strains were used: $(\mathrm{C} 57 \mathrm{BL} / 6 \times \mathrm{CBA}) \mathrm{F}_{1}$ (noted C57/CBA), BALB/c (Janvier), H-2Z1 (Cohen-Tannoudji et al., 1992), Dlx5/6-Cre (http://jaxmice.jax.org/strain/008199.html) in which Cre recombinase (Cre) expression, directed by regulatory sequences of the zebrafish $d l x 5 a / d l x 6 a$, targets differentiating and migrating forebrain GABAergic neurons during embryonic development, and the ROSA26RYFP (http://jaxmice.jax.org/strain/006148.html) reporter line. All postnatal animals were irreversibly anesthetized before transcardiac perfusion with buffered $4 \%$ paraformaldehyde (PFA). Brains were dissected and either rinsed in PBS for 4-chloro-5-bromo-3-indoyl- $\beta$-Dgalactopyranoside (X-gal) staining or postfixed overnight in 4\% PFA at $4^{\circ} \mathrm{C}$ for in situ hybridization and immunohistochemistry. Embryos were obtained from irreversibly anesthetized pregnant mice following a protocol approved by the Veterinary Services of Paris and the CNRS (B-75$05-20)$. The brains were soaked for $2 \mathrm{~d}$ at $4^{\circ} \mathrm{C}$ in $30 \%$ sucrose in PBS before sectioning at $35 \mu \mathrm{m}$ with a freezing microtome.

Fluorescent in situ hybridization. Hybridization to chromosome spreads was performed using standard protocols (Pinkel et al., 1986; Matsuda et al., 1992). Briefly, metaphase spreads were prepared from an $\mathrm{H}-2 \mathrm{Z} 1$ hemizygous female mouse. Concanavalin A-stimulated lymphocytes were cultured at $37^{\circ} \mathrm{C}$ for $72 \mathrm{~h}$ with 5 -BrdU added for the final $6 \mathrm{~h}$ of culture $(60 \mu \mathrm{g} / \mathrm{ml}$ medium) to ensure chromosomal R-banding. lac $Z$ DNA probe was biotinylated by nick translation, mixed with hybridization solution at a final concentration of $10 \mu \mathrm{g} / \mathrm{ml}$, and used at $100 \mathrm{ng}$ per slide. The hybridized probe was detected by means of fluorescence isothiocyanate-conjugated avidin. Chromosomes were counterstained with propidium iodide. A total of 50 metaphase cells was analyzed.

Cloning of transgene integration site flanking sequences. Inverse PCR was performed using EcoRV-digested $\mathrm{H}-2 \mathrm{Z} 1$ hemizygous tail-tip DNA as described previously (Lavenu et al., 1996). Briefly, diluted digested DNA $(0.25 \mathrm{ng} / \mu \mathrm{l})$ was incubated with T4 DNA ligase for $16 \mathrm{~h}$ at $15^{\circ} \mathrm{C}$ and amplified by PCR for 35 cycles using as primers lacZ5663F, cat ggg agc cta ctt ccc gtt ttt ccc gat ttg gct, and lacZ5594R, gga ttt cct tac gcg aaa tac ggg cag aca tgg cet gcc cgg t. A $2.5 \mathrm{~kb}$ PCR product was subcloned into pCR2.1 TOPO vector (Invitrogen) and sequenced. Southern blot was performed with a 205 bp probe generated by PCR using primers H-2ZF, atg gac tct tat ccc cct tgg t, and H-2ZR, tgg agc ctc taa ccc aat gca. To discriminate embryos hemizygous and homozygous for $\mathrm{H}-2 \mathrm{Z} 1$ transgene integration, PCR genotyping was performed with primers $\mathrm{H}-2 \mathrm{ZF} 2$ : cag gct gtt tgt ggc ctc act, H-2ZR, and lacZ5663F. Primers H-2ZF2 and H-2ZR generate a $236 \mathrm{bp}$ from the wild-type locus, and primers H-2ZR and lacZ5663F generate a $497 \mathrm{bp}$ after transgene integration.

Histology. For X-gal staining, Vibratome or frozen brain or flattened cerebral cortex sections or whole dissected brains were reacted overnight at $30^{\circ} \mathrm{C}$ in PBS containing $2 \mathrm{~mm} \mathrm{MgCl}_{2}, 4 \mathrm{~mm} \mathrm{~K}_{4} \mathrm{Fe}(\mathrm{CN})_{6}, 4 \mathrm{~mm}$ $\mathrm{K}_{3} \mathrm{Fe}(\mathrm{CN})_{6}, 4 \mathrm{mg} / \mathrm{ml} \mathrm{X}$-gal, and $0.1 \%$ Triton X-100.

In situ hybridization was performed on freely floating frozen or vibratome sections as described previously (Bally-Cuif and Wassef, 1994) with minor modifications. NBT/BCIP was used as blue substrate for in situ revelation. The following cDNA plasmids were used: SATB1 (IMAGE: 3376441), Tbcld5 (IMAGE: 4159248), ROR $\beta$ (IMAGE: 6469126), SATB2 (gift from V. Tarabykin, Charité, Berlin, Germany), DAZ-like (IMAGE: 1852783), Plc-12 (IMAGE: 5701941), Btg3 (IMAGE: 4457150), Lhx6 (gift from S. Garel, IBENS, Paris, France), and Sst (gift from D. Karagogeos, IMBB, Heraklion, Greece).

Immunocytochemistry was performed as described previously (Louvi et al., 2003), digitonin $(100 \mu \mathrm{g} / \mathrm{ml})$ was substituted to Triton X-100 for immunostaining of DiI-labeled vibratome sections, and $0.2 \%$ glutaraldehyde was added in the fixative for GABA immunodetection. For colabeling transcripts and proteins, in situ hybridization was performed before immunofluorescence. Frozen sections of fixed and cryoprotected brains or Vibratome sections were incubated overnight at $4^{\circ} \mathrm{C}$ in appropriate primary antibodies including the following: goat anti-Satb1 (1:250 or 1:1000; N14; Santa Cruz), rabbit anti-serotonin transporter (SERT) (1/500; Calbiochem), mouse anti-Satb2 (1:200; clone SATB A4B10; Abcam), rabbit anti-CDP/Cux1 (1:500; Santa Cruz), rat anti-Ctip2 (1:500; clone 25B6; Abcam), rabbit anti-Tbr1 (1/500; Abcam), rabbit anti-GABA (1/500; Sigma-Aldrich), chicken anti-GFP (1/500; Aves Labs), and rat anti-Somatostatin (Sst) (1/50; Millipore). After several rinses, speciesspecific fluorescent secondary antibodies (Jackson ImmunoResearch; $1: 1000)$ were incubated for $1 \mathrm{~h}$. In some cases, biotinylated anti-goat (1:300; Jackson ImmunoResearch) followed by avidin-biotin peroxidase complex (1:400; GE Healthcare) were used for peroxidase revelation of Satb1. Sections were counterstained with bisbenzimide or Draq5. For DiI crystal insertion, fixed E18.5 or P1 brains were embedded in 3\% agarose. A coronal section through the block was used to gain access to the corpus callosum where DiI crystals were inserted. The blocks were incubated at $37^{\circ} \mathrm{C}$ for $48 \mathrm{~h}$, and 50 - or $100-\mu \mathrm{m}$-thick vibratome sections were cut and immunostained for Satb1 and Satb2.

Cell counts. Thirty-six-micrometer-thick frozen sections of E18.5 (C57/CBA background) or P1 (BALB/c) wild-type $(n=3)$ and $\mathrm{H}-2 \mathrm{Z1}$ / $\mathrm{H}-2 \mathrm{Z1}(n=3)$ littermates were treated by immunohistochemistry for the detection of Satb1 together with either Satb2, Ctip2, Tbr1, or Cux1, and then counterstained with draq5 (Cell Signaling). Single-optical sections (3.6 $\mu \mathrm{m}$ thickness; $12-20$ scans), three-channels images were acquired with 20 or $25 \times$ objectives using Leica SP 2 or SP 5 confocal microscopes. Cell counts were performed on 100 - $\mu$ m-wide columns using the cell counter plug-in of the ImageJ software and reported to the total number of draq 5 cells. For statistical analysis, the distribution of the results was tested with a Shapiro-Wilk test, followed by an $f$ test. A $t$ test was then applied, and the result summarized as follows: ${ }^{* *} p<0.05 ;{ }^{* *} p<0.001$. The lateral amygdalar nucleus (LA) and basolateral amygdalar nucleus (BLA) amygdalar nuclei were outlined on Tbr1/Satb1/Sstimmunostained sections, and their area was calculated with ImageJ. The areal density of Sst-immunoreactive neurons and the proportion of Sst/ Satb1 coexpression were quantified. The proportion of Sst + bed nucleus of the stria terminalis (BST) neurons that coexpressed Satb1 was calculated on $>200$ Sst + neurons.

\section{Results}

\section{Expression of the $\mathrm{H}-2 \mathrm{Z} 1$ transgene is modified by} genetic backgrounds

Since its generation, the $\mathrm{H}-2 \mathrm{Z} 1$ transgenic line had been maintained by crossing hemizygous males with $(\mathrm{C} 57 \mathrm{BL} / 6 \times \mathrm{CBA}) \mathrm{F}_{1}$ females. In this genetic context (called C57/CBA hereafter), expression of the $\mathrm{H}-2 \mathrm{Z} 1$ transgene precisely delineates the somatosensory area and is restricted to a subset of layer IV neurons (layer IV pattern; Fig. $\left.1 A, A^{\prime}, A^{\prime \prime}\right)$. We previously reported that $\mathrm{H}-2 \mathrm{Z} 1$ cortical expression became wider and more intense in crosses involving BALB/c genetic background (Gitton et al., 1999b). To extend this observation, we crossed $\mathrm{H}-2 \mathrm{Z} 1$ mice with animals from five inbred laboratory strains and monitored $\mathrm{H}-2 \mathrm{Z} 1$ cortical 


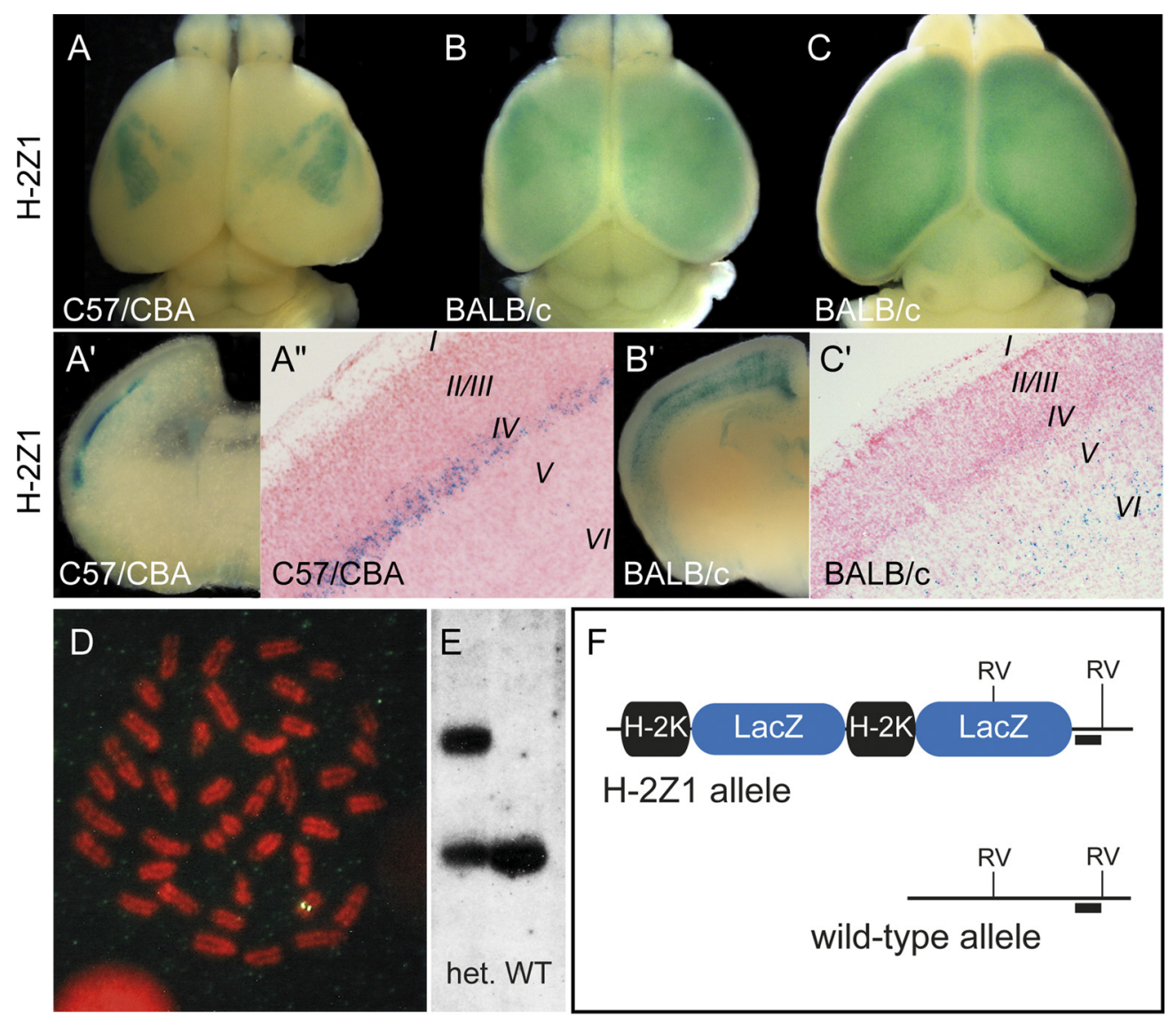

G

Chromosome 17

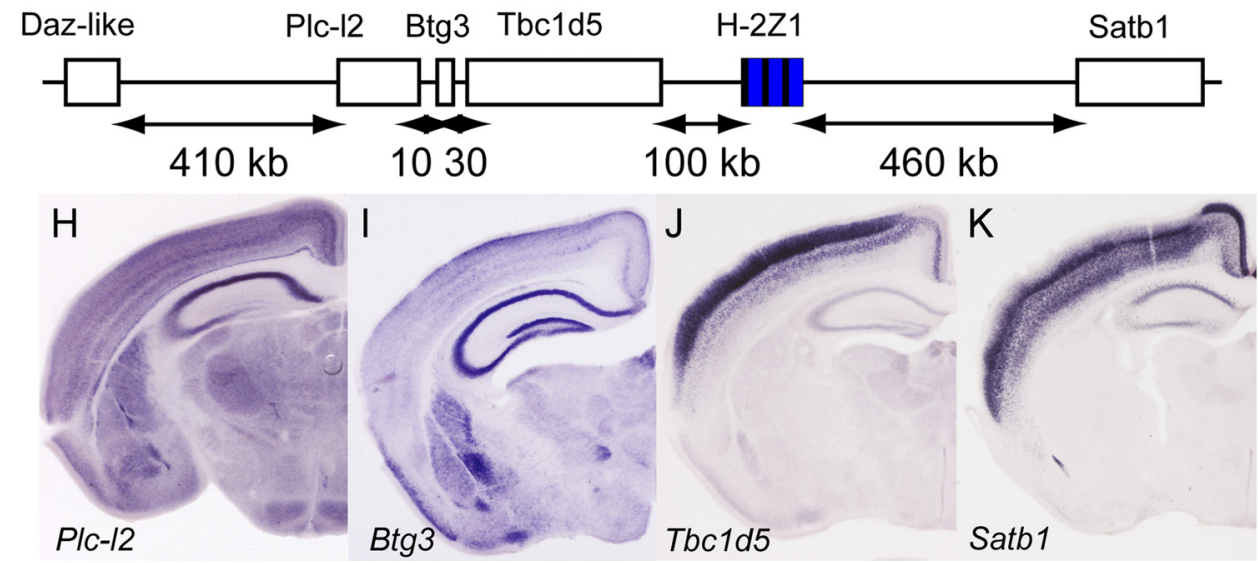

Figure 1. The H-2Z1 transgene. $A-C^{\prime}$, Influence of the genetic background on $H-2 Z 1$ somatosensory expression. The $H-2 Z 1$ transgene was maintained on two distinct backgrounds, $C 57 /\left(B A A\left(A, A^{\prime}, A^{\prime \prime}\right)\right.$ and $B A L B / C\left(B, B^{\prime}, C, C^{\prime}\right)$. X-gal staining was used to reveal H-2Z1 expression on whole P6 brains $\left(A, A^{\prime}, \boldsymbol{B}, \boldsymbol{B}^{\prime}, \boldsymbol{C}\right)$ or on frozen sections $\left(\boldsymbol{A}^{\prime \prime}, \boldsymbol{C}^{\prime}\right)$. On a C57/CBA background, $\mathrm{H}-2 Z 1$ was expressed in the somatosensory area $(A)$ in layer IV neurons $\left(A^{\prime}, A^{\prime \prime}\right)$, In BALB/c pups, X-gal staining was detected, in addition, in a widely distributed population of scattered infragranular neurons. Expression of $\mathrm{H}-2 Z 1$ in layer IV neurons was always less intense than on $C_{57 / C B A}$ background and sometimes barely detectable $\left(\boldsymbol{C}, \boldsymbol{C}^{\prime}\right)$. D, Fluorescent in situ hybridization to metaphase chromosomes prepared from $\mathrm{H}-2 \mathrm{Z} 1 \mathrm{splenocytes} \mathrm{showing} \mathrm{transgene}$ localization to chromosome 17 D-E1. E, Southern blot detection of H-2Z1 integration site (het) and wild-type locus (WT). F, Schematic representation showing the structure of the $3^{\prime}$ end of the head to tail transgene array and the position of the Southern blot probe (black box) used to identify the predicted $2.6 \mathrm{~kb}$ EcoRV (RV) fragment in H-2Z1 hemizygous DNA in addition to a $1.7 \mathrm{~kb}$ wild-type fragment. $G$, Organization of the genes flanking the $\mathrm{H}-2 \mathrm{ZZ}$ transgene (hatched blue box) on Chromosome $17 . \boldsymbol{H}-\boldsymbol{K}$, Expression patterns in the P7 cerebral cortex of four genes located in the genome near the insertion site of $\mathrm{H}-2 Z 1$. While PIC-12 (H) and Btg3 (I) show a large (including cortical) expression, both $\operatorname{Tbc} 1 \mathrm{~d} 5(\boldsymbol{J})$ and Satb1 $(\boldsymbol{K})$ are intensely expressed in the cerebral cortex.

expression in the corresponding progenies (Table 1). We found that the proportion of animals exhibiting layer IV pattern not only varied from one inbred strain to another but also depended on whether the transgene was transmitted by the male or the female. Therefore, $\mathrm{H}-2 \mathrm{Z} 1$ cortical expression seems to be modified by genetic backgrounds in a complex manner. We then crossed $\mathrm{H}-2 \mathrm{Z} 1$ hemizygous male to BALB/c females for several generations and analyzed the modified cortical expression pattern (Fig. $1 B, B^{\prime}, C, C^{\prime}$ ). In this genetic setting (called $\mathrm{BALB} / \mathrm{c}$ hereafter), the $\mathrm{H}-2 \mathrm{Z1}$ transgene was expressed in the cingulate cortex as well as in a population of neurons scattered in the infragranular layers of all cortical regions (Fig. $1 B^{\prime}, C^{\prime}$ ). Expression of H-2Z1 in somatosensory cortex layer IV neurons was always less prominent in BALB/c (mixed pattern; Fig. $1 B, B^{\prime}$ ) than in 


\begin{tabular}{|c|c|c|c|}
\hline Cross (dam $\times$ sire) & No. of transgenic pups analyzed & Layer IV profile & Wider profile \\
\hline C57BL/6 $\times$ H-2Z1 & 19 & 18 & 1 \\
\hline $\mathrm{H}-2 \mathrm{ZZ} \times \mathrm{C} 57 \mathrm{BL} / 6$ & 17 & 8 & 9 \\
\hline $\mathrm{BALB} / \mathrm{C} \times \mathrm{H}-2 \mathrm{Z1}$ & 24 & 3 & 21 \\
\hline $\mathrm{H}-2 \mathrm{Z1} \times \mathrm{BALB} / \mathrm{C}$ & 15 & 15 & 0 \\
\hline $\mathrm{DBA} 2 \times \mathrm{H}-2 \mathrm{Z} 1$ & 6 & 6 & 0 \\
\hline $\mathrm{H}-2 \mathrm{Z1} \times \mathrm{DBA2}$ & 7 & 7 & 0 \\
\hline $\mathrm{AJ} \times \mathrm{H}-2 \mathrm{Z1}$ & 8 & 2 & 6 \\
\hline $\mathrm{H}-2 \mathrm{Z1} \times \mathrm{AJ}$ & 16 & 15 & 1 \\
\hline $\mathrm{C} 3 \mathrm{H} \times \mathrm{H}-2 \mathrm{Z1}$ & 20 & 12 & 8 \\
\hline $\mathrm{H}-2 \mathrm{Z1} \times \mathrm{C} 3 \mathrm{H}$ & 10 & 7 & 3 \\
\hline
\end{tabular}

C57/CBA genetic background (Fig. 1, compare $A^{\prime}, B^{\prime}$ ). In some $\mathrm{BALB} / \mathrm{c}$ transgenics, $\mathrm{H}-2 \mathrm{Z} 1$ expression was barely detectable in layer IV neurons (deep layers pattern; Fig. $1 C, C^{\prime}$ ).

Genetic background also impinged on the viability of $\mathrm{H}-2 \mathrm{Z} 1$ homozygous mice. Indeed, using progeny testing, we were unable to identify homozygous mice on a C57/CBA genetic background. Recovery of the genomic sequence directly flanking the $3^{\prime}$ copy of the transgene (see below) allowed us to identify homozygous individuals by PCR genotyping. While no homozygous mice were found among P14 littermates, normal proportions of E11.5 to E18.5 homozygous embryos were recovered, suggesting that $\mathrm{H}-2 \mathrm{Z} 1$ insertion at the homozygous state was lethal at birth or during the first weeks of life in a C57/CBA background. In contrast, homozygous mice were observed at the expected frequency in $\mathrm{BALB} / \mathrm{c}$ intercrosses. On this genetic background, homozygous mice survived to adulthood and were fertile.

\section{Identification of the $\mathrm{H}-2 \mathrm{Z} 1$ transgene insertion site and flanking genes}

The organization of the transgene integration site was studied by Southern blot analysis, which revealed multiple copies integrated in a head-to-tail configuration (data not shown). Fluorescent in situ hybridization (FISH) with a lacZ probe allowed us to map transgene integration site to chromosome 17 D-E1 (Fig. 1D). Then, an inverse PCR strategy, with primers in the $3^{\prime}$ region of the $l a c Z$ gene and directed in opposite directions, was used to recover a transgene-integration site junction fragment containing $231 \mathrm{bp}$ of flanking sequence. Consistent with the FISH mapping data, this sequence aligned with the central portion of chromosome 17. Southern blot and PCR analyses confirmed the presence of this junction specifically in DNA from mice carrying the $\mathrm{H}-2 \mathrm{Z} 1$ transgene (Fig. $1 E, F$ ). Such analyses also revealed that a region of $\sim 22 \mathrm{~kb}$ of genomic sequences was deleted following transgene integration (data not shown).

Based on the lethality of homozygous mice on a C57/CBA genetic background, we expected that the transgene integrated into or in the close vicinity of an essential gene causing its disruption. Surprisingly, sequence alignment revealed that $\mathrm{H}-2 \mathrm{Z} 1$ was inserted in a large intergenic region $(560 \mathrm{~kb})$ containing $70-80 \%$ of repeated sequences. We therefore searched for genes in an interval of $1 \mathrm{Mb}$ centered on H-2Z1 insertion site (Fig. 1G). The following five genes were identified: Daz-like (Unigene Mm15050), the autosomal homolog of the Y-linked gene deleted in azoospermia (Cooke et al., 1996); Plc-l2 (Mm28034), coding for a phospholipase C-related inactive protein involved in B-cell receptor regulation (Takenaka et al., 2003); Btg3 (Mm2823), coding for an antiproliferative protein abundant in neuroepithelium (Yoshida et al., 1998; Yoneda et al., 2009); Tbc1d5 (Mm182469), a TBC domain-containing gene encoding a member of the Rab GAP family of proteins, which interacts with retromer (Ishibashi et al., 2009; Seaman et al., 2009); and Satb1, encoding a nuclear scaffold protein, the special AT-rich sequence-binding protein 1 (Mm4381), involved in long-range chromatin rearrangement (Dickinson et al., 1992; Cai et al., 2003). We refer to these genes hereafter as the H-2Z1 flanking genes. ESTs were selected to examine their expression patterns by in situ hybridization in the P7 mouse cerebral cortex. Plc-l2 (Fig. $1 \mathrm{H}$ ) and Btg3 (Fig. 1I) were rather ubiquitously expressed, whereas Daz-like was not expressed in the brain (data not shown). Tbc1d5 (Fig. 1J) and Satb1 (Fig. $1 K$ ) displayed distinct layer-specific expressions, and both were expressed at high level in layer IV. Tbcld5 and Satb1 were also the genes closest to the $\mathrm{H}-2 \mathrm{Z1}$ insertion site (Fig. $1 G$ ).

To investigate whether the H-2Z1 flanking genes were expressed in the somatosensory area (S1), we performed in situ hybridizations on 100- $\mu$ m-thick sections of wild-type P5 and P9 flattened cortices. The typical cytological organization of layer IV neurons in the barrel cortex is readily detectable on such sections. Satb1 (Fig. 2A, Satb1) and Tbc1d5 (Fig. 2A, Tbc1d) were both intensely expressed in the barrel cortex at P5 and P9, and at somewhat lower level in the motor, visual, and auditory areas. In addition, we observed that $\mathrm{Plc}$ - 12 (Fig. $2 \mathrm{~A}, \mathrm{Plc}$ - $l 2$ ) was enriched in the barrel walls, a pattern similar to that of H-2Z1 (Gitton et al., 1999a). Expression of Btg3 on flat mounts (Fig. 2A, Btg3) was faint and ubiquitous but still detectable in the somatosensory area. Thus, all the H-2Z1 flanking genes are expressed in layer IV neurons of the somatosensory area.

\section{Brain and body expressions of $\mathrm{H}-2 \mathrm{Z} 1$, Satb1, and Tbc1d5}

At first sight, the wider expression pattern of $\mathrm{H}-2 \mathrm{Z} 1$ in the cerebral cortex of BALB/c mice resembled more that of the flanking Satb1 and Tbcld5 genes than the somatosensory specific pattern observed in C57/CBA mice (Fig. 1, compare $A^{\prime}, B^{\prime}$, with $G, H$ ). The variability in $\mathrm{H}-2 \mathrm{Z} 1$ expression patterns could report a strain difference in the expression of Satb1 or Tbcld5 in BALB/c and C57/CBA wild-type mice. Such strain difference was, however, not observed by in situ hybridization (Satb1, Tbc1d5) or immunocytochemistry (Satb1). Thus, the strain-specific genetic modifiers that act on the $\mathrm{H}-2 \mathrm{Z} 1$ enhancer trap expression profile may not affect the expression pattern of the Satb1, Tbcld5 genes in wild-type mice. Even if its somatosensory area-specific expression has driven more attention, the $\mathrm{H}-2 \mathrm{Z1}$ transgene is also expressed in several additional brain and body sites (CohenTannoudji et al., 1992). We therefore performed a survey of the H-2Z1, Satb1, and Tbc1d5 extracortical expression sites during development. We observed that $\mathrm{H}-2 \mathrm{Z} 1$ and Satb1 are similarly expressed in the basal pons and trochlear nuclei at E14.5 (Fig. 2 B) and P9 (Fig. 2C), whereas Tbc1d5 is not or faintly expressed in these regions during development (Fig. $2 B, C$ ). Around birth, expression of Satb1 and H-2Z1 in the cerebellum is restricted to the fastigial nucleus (Fig. 2D). Outside the brain, Satb1 and $\mathrm{H}-2 \mathrm{Z1}$ are coexpressed in the developing thymus (CohenTannoudji et al., 1992; Alvarez et al., 2000) and in tooth primordial (Cohen-Tannoudji et al., 1992) (Allen Brain Atlas, Satb1E15.5100083793). Thus, Satb1, but not Tbc1d5, shares most of the extracortical brain and body expression sites of $\mathrm{H}-2 \mathrm{Z} 1$.

While H-2Z1 and Satb1 clearly share most of their expression sites, it is more difficult to assess to what extent they colocalize at the cellular level. In $\mathrm{H}$-2Z1-positive neurons, $\beta$-galactosidase activity is detected as one or more cytoplasmic dots (Gitton et al., $1999 b)$. On frozen sections, this subcellular localization of $\beta$-galactosidase activity biases the detection of $\mathrm{H}$-2Z1-positive 
A
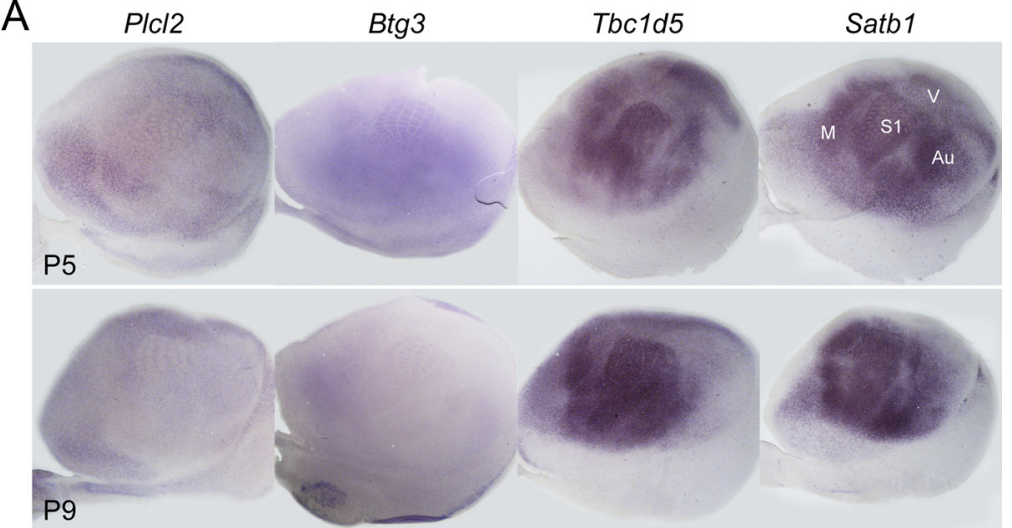

B $\mathrm{H}-2 \mathrm{Z1}$ Satb1 Tbc1d5
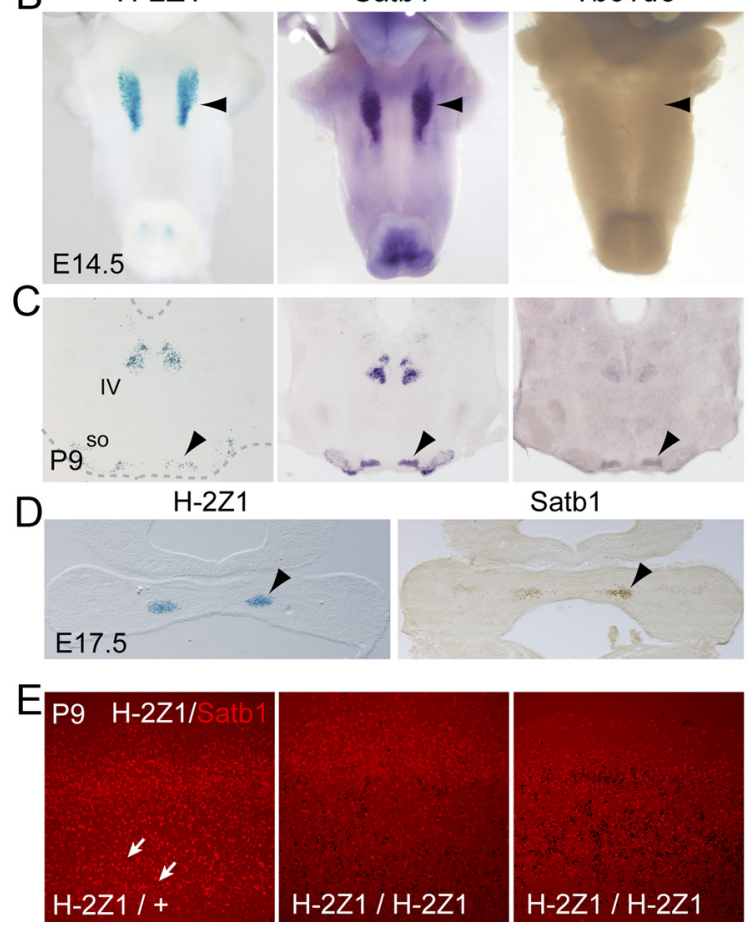

Figure 2. Expression patterns of genes adjacent to the $\mathrm{H}-2 Z 1$ insertion site. A, Expression of $\mathrm{H}-2 Z 1$ flanking genes $P I C I 2, B t g 3$, $T b c 1 d 5$, and $S a t b 1$ revealed by in situ hybridization in $100-\mu \mathrm{m}$-thick sections of flattened cortices (anterior is left; dorsal is up). The four genes are expressed in the barrel cortex (S1). $\boldsymbol{B}-\boldsymbol{E}$, Expression of $\mathrm{H}-2 \mathrm{Z} 1$ was detected by $X$-Gal staining, expression of Satb 1 and $T b c 1 d 5$ was revealed by in situ hybridization $(\boldsymbol{B}, \boldsymbol{C})$. The Satb1 protein was also detected by immunocytochemistry $(\boldsymbol{D}, \boldsymbol{E}) \cdot \boldsymbol{B}$, Ventral views of E14.5 brains treated in toto to illustrate the similarity of $\mathrm{H}-2 \mathrm{Z1}$ and Satb1 expressions in the pontine region (arrowheads) and spinal cord at this stage. $T b c 1 d 5$ is not expressed in the hindbrain at this stage. C, Coronal sections in the pontine region of P9 $\mathrm{H}-2 \mathrm{Z1}$ transgenic. $\mathrm{H}-2 \mathrm{Z1}$ and Satb1 are coexpressed in the basal pons (arrowhead), the superior olive (so), and the trochlear nucleus (IV). Tbc1d5 expression is barely detectable above background staining in these nuclei. D, At E17.5, H-2Z1 and Satb1 are coexpressed in the fastigial nucleus (arrowhead) of the cerebellum. $\boldsymbol{E}, \mathrm{P9}$ cortex of $\mathrm{H}-2 \mathrm{Z1} /+$ and homozygous (H-2Z1/H-2Z1) pups treated for the detection of $\mathrm{H}-2 \mathrm{Z1}$ ( $\mathrm{X}$-gal, dark dots, arrows in the first panel) and Satb1 (red immunofluorescence) coexpression. The sections were imaged under combined transmitted and incident light. S1, Primary somatosensory cortex; M, motor cortex; V, visual cortex; Au, auditory cortex.

cells, especially at low magnifications. The visualization of clustered cells is favored, while scattered cells are barely detectable, even when intensely $\beta$-galactosidase positive (Fig. 1 , compare $A^{\prime \prime}$, $C^{\prime}$, for example). This cytological property of the H-2Z1 transgene prevented the precise quantification of $\mathrm{H}-2 \mathrm{Z} 1$ and Satb1 colocalizations. In situ hybridization for lac $Z$ could not be used as an alternative to visualize the $\beta$-galactosidase-expressing cells because of the low level of expression of $\mathrm{H}-2 \mathrm{Z} 1$. Nevertheless, it is clear that the expression patterns of Satb 1 and $\beta$-galactosidase are related but not identical. In deep cortical layers (Fig. $2 E$ ), no strict correlation was found between X-gal staining and Satb1 immu- nofluorescence. The presence of two copies of the $\mathrm{H}-2 \mathrm{Zl}$ transgene (Fig. $2 E$, $\mathrm{H}-2 \mathrm{Z1} / \mathrm{H}-2 \mathrm{Z1}$ ) markedly increased X-gal staining intensity, but X-gal/Satb1 cellular colocalization was still partial. Thus, $\mathrm{H}-2 \mathrm{Z} 1$ shares some features of its cortical expression pattern with its four flanking genes and a large number of common expression sites with Satb1. Nevertheless, Satb1 and $\mathrm{H}-2 \mathrm{Z1}$ are not precisely coexpressed.

\section{Tangential modulation of Satb 1 expression in the postnatal cerebral cortex}

We focused on Satb1 for several reasons. $S a t b 1$ is highly expressed in the barrel cortex (Fig. 2A, Satb1), Satb1 and H-2Z1 share several noncortical expression sites (Fig. 2B-D), the Satb1 closely related chromatin modifier Satb2 is involved in layer type neuronal specification in the cerebral cortex (Alcamo et al., 2008; Britanova et al., 2008). Finally, several anti-Satb1 antibodies are commercially available, allowing characterization of the Satb1-expressing cell types. The pattern of Satb1 expression described below is based primarily on in situ hybridization and immunohistochemistry performed on cerebral cortex sections of BALB/c embryos and pups. Except for small variations in the overall maturity of embryos fixed at a given age, no strain-specific differences were detected in the pattern of Satb1 expression between "BALB/c," C57/CBA, and Swiss mice at embryonic or postnatal stages.

We first examined whether the chronology of Satb1 expression involves a tangential or area-specific component. Satb1 was uniformly expressed along the dorsoventral extent of the cortex in $\mathrm{BALB} / \mathrm{c}$ embryos (Fig. 3A, E14.5) and newborn pups (Fig. 3A, P1). Satb1 transcripts were also expressed in the neuroepithelium of the pallium and subpallium at E14.5, but the Satb1 protein was not detected. At P1, the domain of $S a t b 1$ expression was wider in the anterior than in the parietal cortex, which comprises the somatosensory cortex. Regional differences in the expression of Satb1 appear at P7 (Fig. 3A, P7). By P9, the most conspicuous site of Satb1 cortical expression is in the somatosensory area both in layer IV and in deep cortical layers (Fig. 3A, P9). To follow the dynamics of Satb1 expression in the somatosensory cortex along the radial dimension, we used SERT immunofluorescence to label the bundle of thalamocortical axons that occupies the barrel centers (Lebrand et al., 1998). We observed a progressive extension of Satb1 labeling from the bottom of the barrels to more superficial regions of the barrelfield (Fig. 3B, P3 to P9), a pattern consistent with that of $\mathrm{H}-2 \mathrm{Z} 1$ in C57/CBA mice (Gitton et al., 1999a). Thus, the pattern of expression of H-2Z1 in C57/CBA transgenics consists in a subdomain of that of Satb1. 


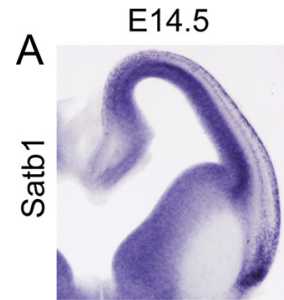

P3

B
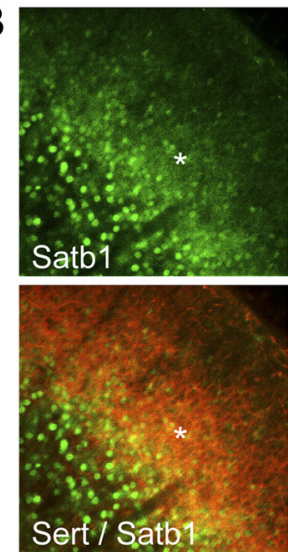

D

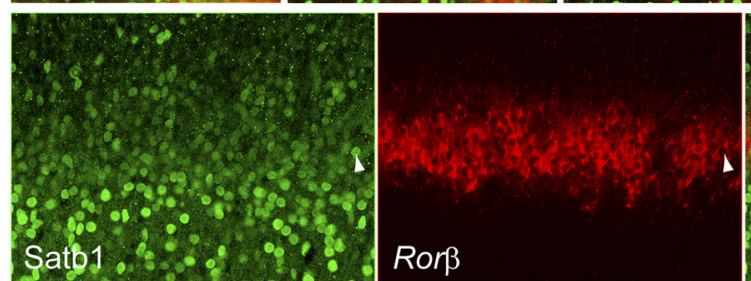

E
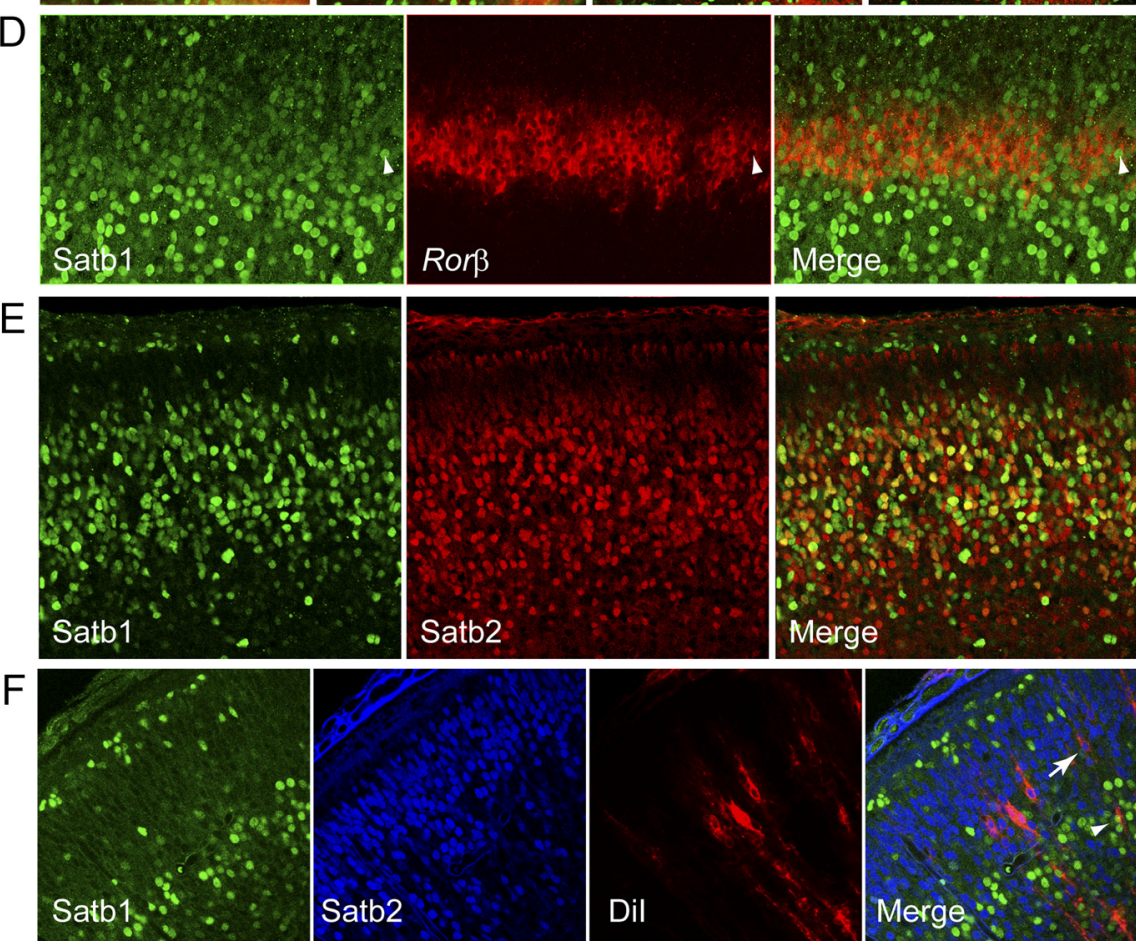

P9

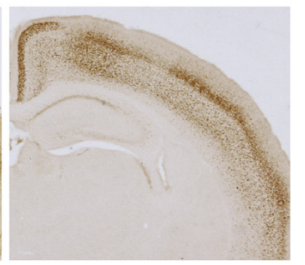

P9

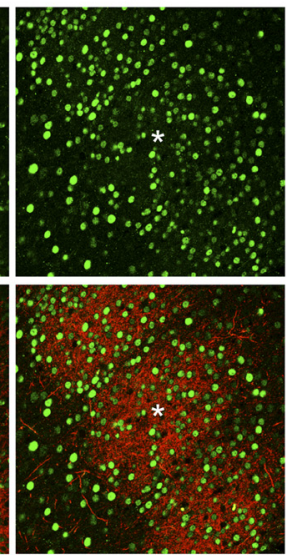

\section{$\mathrm{C}$}
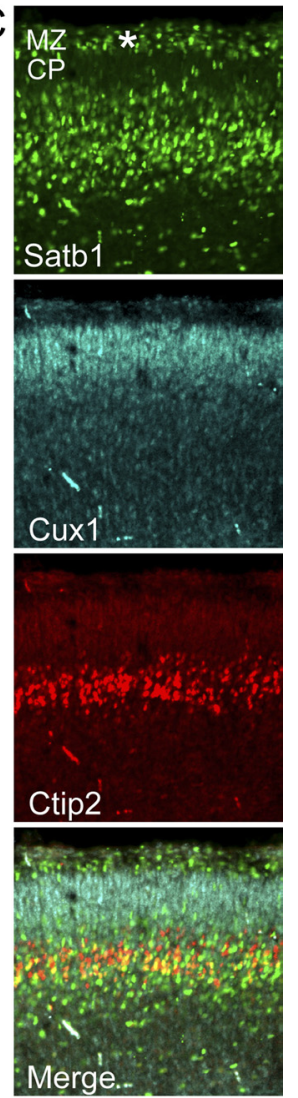

Figure 3. Characterization of cortical layer neuronal types expressing Satb1. $A$, Coronal sections through the forebrain of developing mice (the stage is indicated above each panel) treated for the detection of Satb1 transcripts (E14.5, purple) or protein (P1, P7, P9, brown). Notice that the planar distribution of the Satb1-labeled neurons is uniform in the cerebral cortex at E14.5 and P1 and becomes regionally modulated by P7. B, Coronal sections through the barrelfield of developing mice treated by immunocytochemistry for the detection of Satb1 (green) and Sert (red), which marks the thalamic axons and outlines the S1 barrels. Notice that Satb1 is accumulated at the bottom of the barrels at P3 and P5. Beginning from P7, and even more at P9, neurons in the barrel wall begin to accumulate Satb1 protein. The asterisks mark the same barrel centers in different channels. $\mathbf{C} \boldsymbol{F}$, Coronal sections through the parietal cortex of perinatal mice colabeled for Satb1 (green immunocytochemistry) with markers of pyramidal neurons. C, Section labeled for Satb1, Cux1 (cortical plate/superficial layers, blue), and Ctip2 (layer V, red). Satb1 is strongly expressed in the marginal zone (star), scarcely expressed in the $C P$, and broadly expressed in deep layers encompassing the domain of Ctip2 expression. $D$, Frozen section through the P2 cortex labeled for the detection of Satb1 protein (green) and RoR $\beta$ transcripts (red, cortical plate/layer IV) showing partial coexpression between RoR $\beta$ and Satb1 (arrowhead). $\boldsymbol{E}$, Double immunohistochemistry for Satb1 and Satb2 reveals a partial overlap. $\boldsymbol{F}$, Commissural neurons (red) traced with Dil from the corpus callosum express Satb2 (arrow) and, in some cases, Satb1 (green) plus Satb2 (arrowhead).

\section{Characterization of the cell types expressing Satb1 in the perinatal cortex}

In the perinatal cortex, Satb1 was expressed in a wide band of developing neurons that extends into layer VI, straddles the row of large Ctip2 + neurons in layer V (Fig. 3C), and reaches the deep part of layer IV identified by the expression of Cux1 in layers II-IV (Fig. 3C). Satb1 is also expressed in marginal cells lying between the pia and the Cux1-positive cells (Fig. 3C, asterisk). Most Satb1-positive neurons were deeper than the row of reelinimmunoreactive cells (data not shown), indicating that Satb1 is 

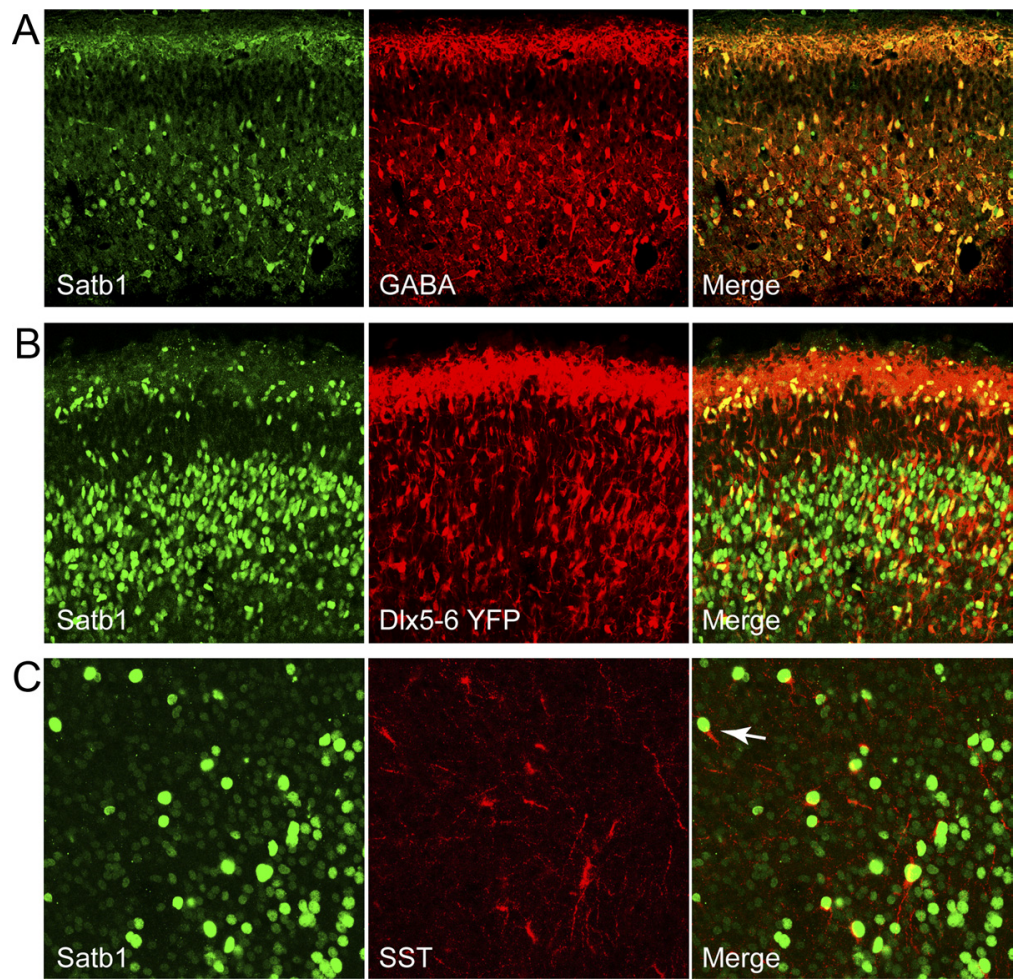

Figure 4. Satb1 is expressed in a subset of cerebral cortex GABAergic interneurons. $\boldsymbol{A}-\boldsymbol{C}$, Coronal sections through the parietal cortex of perinatal mice colabeled for Satb1 (green) with markers of GABAergic interneuron. $\boldsymbol{A}$, Satb1 and GABA (red) were largely coexpressed. $\boldsymbol{B}$, Satb1 was expressed in a subset of Dlx5/6-Cre-labeled neurons (red). $\boldsymbol{C}$, The great majority of the Sst + cortical interneurons (red neurites) coexpress Satb1 (arrow).

not expressed in Cajal-Retzius cells. To characterize the Satb1positive populations of cortical neurons, we performed multiple immunofluorescent or in situ hybridization labeling combining detection of Satb1 with other layer or neurotransmitter-specific neuronal markers on sections of perinatal cerebral cortex (between E17.5 and P2).

Like the $\mathrm{H}-2 \mathrm{Z} 1$ transgene, Satb1 is expressed at $\mathrm{P} 2$ in a subset of layer IV neurons marked by in situ hybridization for Ror $\beta$ transcripts (Fig. 3D). Satb1 is also expressed in nongranular neuronal types. At this stage, Satb1 extensively colocalizes in layer V with Ctip2 (Fig. $3 C$ ) and with Satb2 (Fig. 3E) (see also Fig. 6 below). On single confocal sections $64 \%$ of the Satb1 + neurons coexpressed high or moderate levels of Ctip2 and the Satb1+Satb2+ coexpressing neurons represented $33.8 \%$ of the Satb1 + neurons and $13.6 \%$ of the Satb2+ neurons. We examined Satb1 and -2 expressions in callosal neurons retrogradely traced by injection of DiI in the corpus callosum. Neurons traced with DiI were in general colabeled for Satb2 (Fig. 3F, arrow) and in some cases for both Satb1 and Satb2 (Fig. 3F, arrowhead). We did not observe callosal neurons single labeled for Satb1. Thus, Satb1 is expressed in a large variety of pyramidal neurons types in the perinatal cortex.

Satb1 was also expressed in a subset of GABAergic interneurons of the E18.5 cerebral cortex. Satb1 and GABA were largely coexpressed (Fig. 4A). Satb1 was also coexpressed with YFP in cortical interneurons labeled from the medial ganglionic eminence (MGE) in Dlx5/6-Cre::ROSA26R-YFP E18.5 transgenics (Fig. $4 B$ ). The cortical GABAergic interneurons comprise a large variety of subtypes with distinct physiological properties associated with different gene expression profiles (Taniguchi et al., 2011). Sst is one of the few endogenous markers of interneuron subtype that is detectable perinatally by immunofluorescence. Sst immunoreactivity was detected in the neurites of a sparse population of cortical interneurons in P2 C57/CBA pups, the Sst-stained neurites abutting the center of the Satb1-fluorescent nucleus. The vast majority $(85.96 \pm 0.59 \% ; n=3)$ of the Sst+ interneurons were colabeled for Satb1 (Fig. 4C). Thus, in addition to pyramidal neurons, Satb1 was expressed in a large population of GABAergic interneurons that comprise the early developing Sst+ neurons.

We examined whether cortical development was altered upon homozygous insertion of the $\mathrm{H}-2 \mathrm{Z} 1$ transgene.

\section{Influence of the $\mathrm{H}-2 \mathrm{Z1}$ transgene on cortical development}

The cerebral cortex of homozygous C57/ CBA transgenic mice was examined on sections of E18.5 embryos labeled for Tbrl and Cuxl and counterstained with Draq5 (Fig. 5A). The cortex was organized normally with clearly defined ventricular zone (VZ)/subventricular zone (SVZ), intermediate zone (IZ), and well organized developing cortical layers (Fig. 5A). Interestingly, we observed that $\mathrm{H}-2 \mathrm{Z1}$ insertion at the homozygous state interfered with the expression of the Satb1 and Tbc1d5 flanking genes. The downregulation of the Satb1 (Fig. 5B,C) and Tbcld5 (Fig. 5D) transcripts in E17.5-E18.5 H-2Z1 embryos was dependent on the number of copies of H-2Z1. Homozygous C57/CBA transgenic embryos were more affected than heterozygous ones. In homozygous transgenics, expression of Satb1 was also decreased outside the cortex in the pons, the cerebellum, and the hindbrain (data not shown). In contrast with Satb1 and Tbc1d5 whose genomic locations flank the $\mathrm{H}-2 \mathrm{Z} 1$ insertion site, other unrelated cortical markers like Ror $\beta$ (Fig. $5 E$ ) or Satb2 (Fig. 5F) were not qualitatively altered in $\mathrm{H}-2 \mathrm{Z} 1$ transgenics compared with controls. We tested whether other genes closer to the $\mathrm{H}-2 \mathrm{Z} 1$ insertion sites were affected in homozygous transgenics beyond Satb1 and Tbcld5. Expression of the two remote H-2Z1 flanking genes Plc-l2 (Fig. 5G) and Btg3 (Fig. 5H) was similar to control in homozygous transgenics. This suggests that insertion of the $\mathrm{H}-2 \mathrm{Z} 1$ transgene specifically affects regulatory sequences controlling expression of the Satb1 and Tbc1d5 genes and does not affect a wide genomic domain. The normal expression of other widely expressed cortical markers suggests that the decrease in Satb1 and Tbc1d5 expressions does not result from the loss of a large population of cortical neurons. Recent studies have shown that $S a t b 2$, a transcriptional regulator closely related to $S a t b 1$, acts as a molecular determinant of upper layer neuron specification (Alcamo et al., 2008; Britanova et al., 2008). The important downregulation of Satb1 expression observed in $\mathrm{H}-2 \mathrm{Z} 1$ transgenics could therefore similarly affect the specification of cortical neurons.

Layer-type neuron specification in the cerebral cortex of homozygous embryos

Although Satb2 expression seemed qualitatively normal, we examined more closely the numbers and relative distributions of 


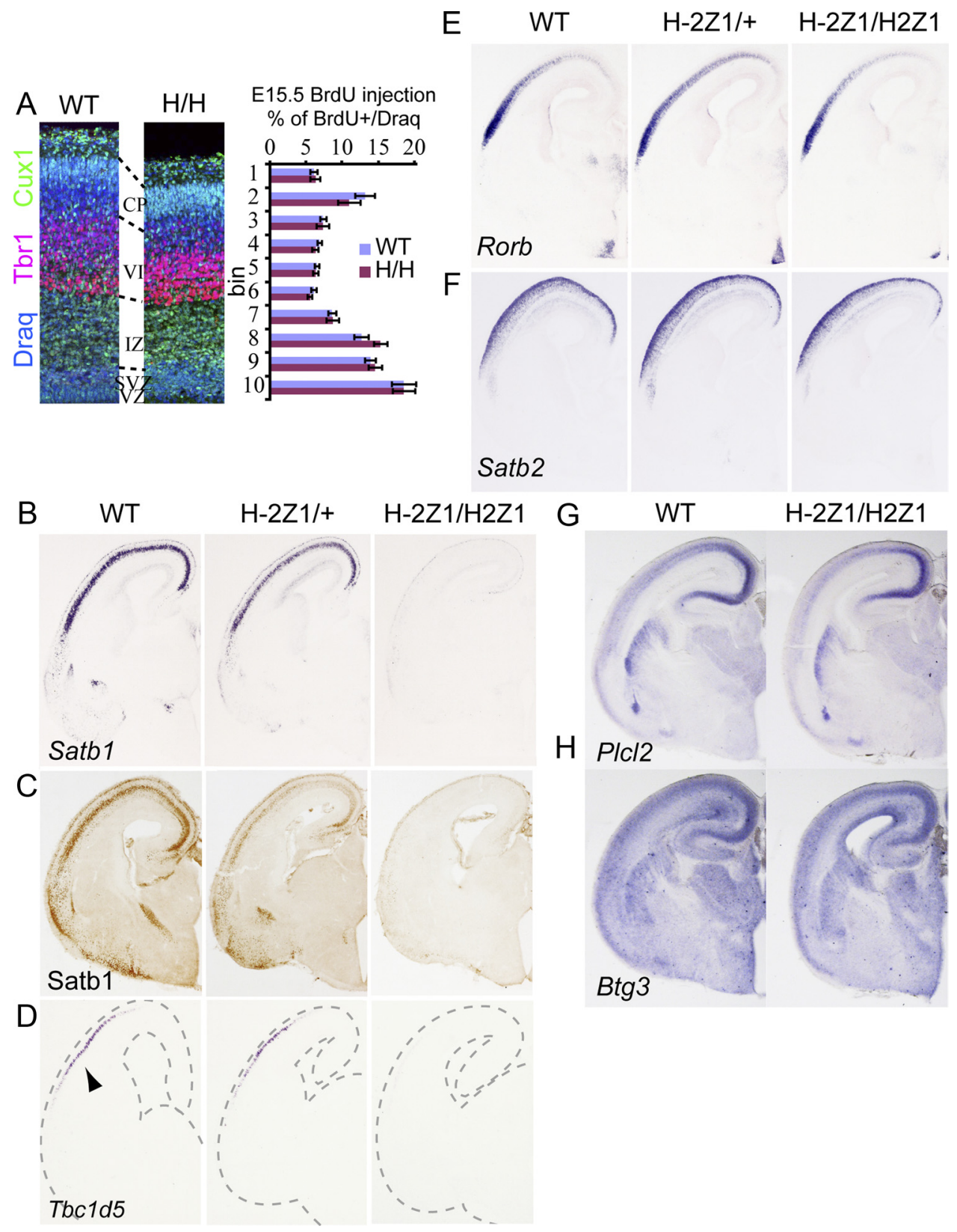

Figure 5. Insertion of the H-2Z1 transgene affects the expression of both Satb1 and Tbc1d5.A, Cortical organization in WT and homozygous (H/H) C57/CBA transgenics. Coronal sections of E18.5 embryos immunolabeled for Tbr1 (red) Cux1 (green) and counterstained with Draq5. The developing cortex is normally organized; the distributions of BrdU cells born at E15.5 are identical in H-2Z1 homozygous embryos and their wild-type littermates at E18.5. $\boldsymbol{B}-\boldsymbol{F}$, Coronal sections through the forebrain of E17.5 C57/CBA embryos containing zero, one, or two copies of the H-2Z1 transgene as indicated on the top of each column. The sections were treated for the detection of $S a t b 1(\boldsymbol{B}), \operatorname{Tbc} 1 d 5(\boldsymbol{D}), \operatorname{Ror} \beta(\boldsymbol{E})$, and $\operatorname{Satb2}(\boldsymbol{F})$ transcripts and of Satb1 protein $(\boldsymbol{C})$. In $\boldsymbol{D}$, to improve the localization of the in situ staining for $T b c 1 d 5$, the sections were outlined with Photoshop. Insertion of the H-2Z1 transgene decreases the expression of Satb 1 and $T b c 1 d 5$ without affecting those of Ror $\beta$ or Satb2. This effect increased with the number of $\mathrm{H}-2 Z 1$ alleles. Expression of the two remote flanking genes PICI2 (G) and Btg3 $(\boldsymbol{H})$ was similar in WT and homozygous transgenics.

Satb1+ and Satb2 + neurons. We counted the number of Satb1-, Satb2-, and Draq5-expressing cells in a 100- $\mu$ m-wide cortical column. In mice homozygous for $\mathrm{H}-2 \mathrm{Z} 1$, Satb1 expression is markedly reduced in all regions of the cerebral cortex, but the rostral cortex is comparatively less affected. The influence of $\mathrm{H}-2 \mathrm{Z} 1$ insertion on the expression of Satb2 and Ctip2 was examined on sections of the parietal cortex, which corresponds both to the site of expression of $\mathrm{H}-2 \mathrm{Z} 1$ in layer IV and avoided the rostral cortex. Three confocal pictures of immunostained frozen sections were obtained from two or three sections taken at similar levels in the parietal cerebral cortex of homozygous or wild-type C57/CBA littermates (three E18.5 pups of each genotype). For each marker, the number of immunoreactive cells was reported to the total number of Draq5-stained cells. The same procedure was used for the other markers described below.

Consistent with our ISH observations (Fig. $5 B, C$ ), the number of Satb1+ cortical neurons was drastically reduced in E18.5 homozygous C57/CBA embryos (Fig. 6, compare $A, B$ ). Although the decrease was qualitatively similar in all $\mathrm{H}-2 \mathrm{Z} 1$ homozygous mutants analyzed at E18.5, the number of Satb1 + cells was much more variable in individual mutants than in wild-type controls. The number of Satb1 cells was quantified in three independent groups of E18.5 cortices, each comprising three WT and three homozygous C57/ CBA transgenics. The sections were colabeled for distinct markers of 

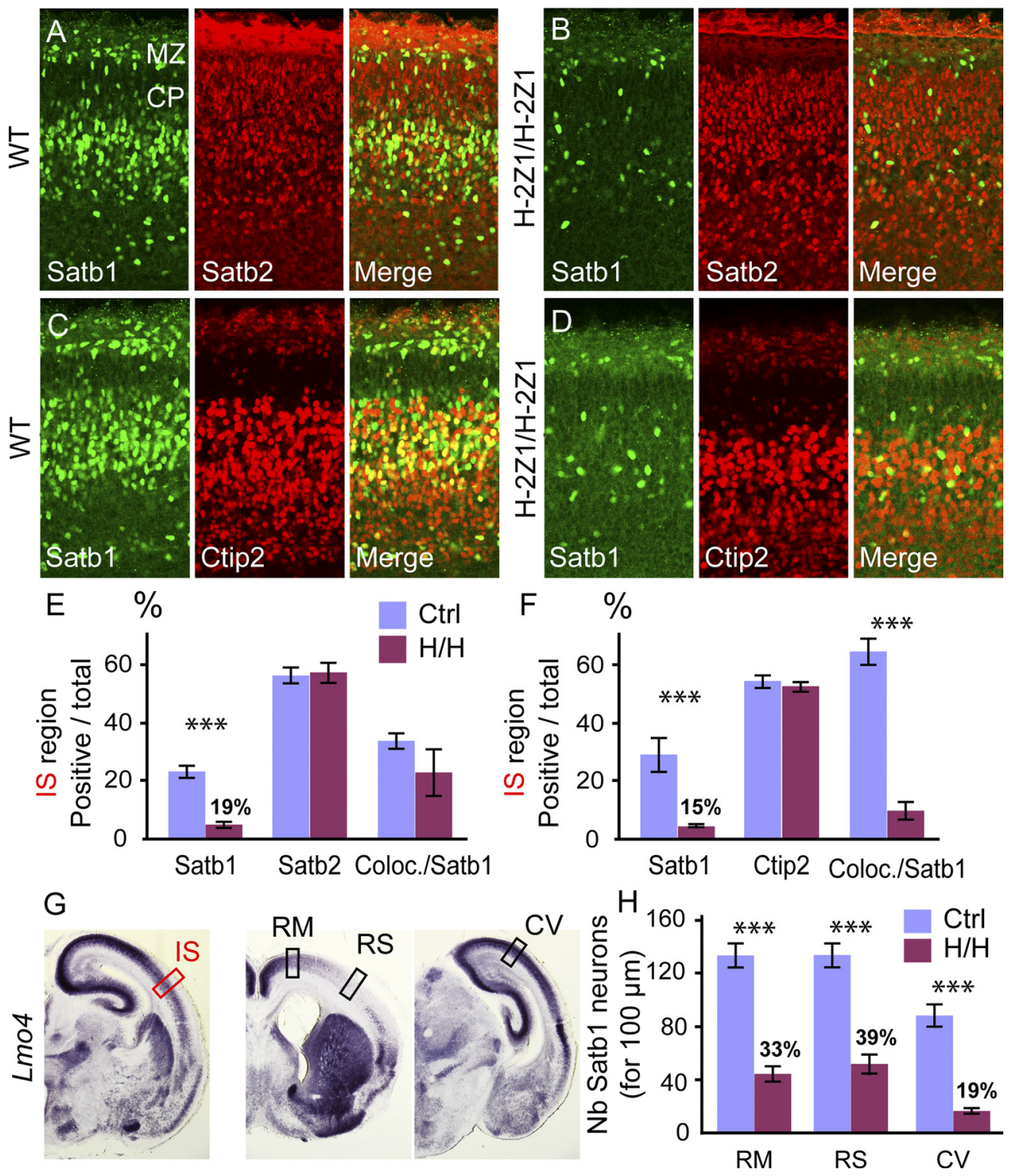

Figure 6. The decrease in Satb1 expression does not affect other layer-type neuronal markers. $A-D$, Confocal images of coronal sections through the intermediate/somatosensory cortex (IS illustrated in $\boldsymbol{G})$ of E18.5 C57/CBA wild-type $(\boldsymbol{A}, \boldsymbol{C})$ and H-2Z1 homozygous ( $\boldsymbol{B}, \boldsymbol{D})$ embryos treated by immunohistochemistry for Satb1 and Satb2 $(\boldsymbol{A}, \boldsymbol{B})$ or Satb1 and Ctip2 $(\boldsymbol{C}, \boldsymbol{D})$ and counterstained with Draq5. The cell counts for Satb1/Satb2 are illustrated in $\boldsymbol{E}$ and in $\boldsymbol{F}$ for Satb1/Ctip2. Neuron numbers for each marker and colocalizations were normalized to the total number of Draq5 + cells. $G$, Coronal sections through the forebrain of 18.5 embryos treated for the detection of $L m 04$ transcripts. The rectangles indicate the sites selected for cell counts using $\mathrm{Lm0} 4$ expression as a landmark. All the layer-marker cell counts were performed in the intermediate/somatosensory cortex (IS), whereas the area-specific cell counts were performed in the rostral/motor (RM), rostral/somatosensory (RS), and caudal/visual (CV) domains. $\boldsymbol{H}$, Quantification of the number of Satb1 + neurons in 100- $\mu \mathrm{m}$-wide cortical columns in the RM, RS, and CV areas. Variation of the decrease in the number of Satb1 + cortical neurons induced by the $\mathrm{H}-2 \mathrm{ZZ}$ mutation is region specific (rostral cortex less affected) but not area specific. ${ }^{* * *} p<0.001$. Error bars indicate SEM.

cortical neuron types in each group. The proportion of Satb1+ cells in the mutants ranged between 15 and 19.4\% of controls $(p<0.001)$ in the three groups. The marginal zone, quantified in a single group, was less affected ( $55 \%$ of controls; $p<0.0006)$. The decrease was similar in $\mathrm{P} 1$ homozygous $\mathrm{BALB} / \mathrm{c}$ transgenics.

At E18.5, the number of Satb2 + neurons was not significantly different from controls in homozygous mutants (Fig. 6A, B,E; $101.8 \%$ of controls; $p=0.8$ ). The Satb $2+$ neurons of the marginal zone were not included in these counts because the antimouse IgG antibodies used to immunolabel Satb2 were found to bind to presumptive $\mathrm{Fc}$ receptors in the meninges interfering in some sections with the detection of the Satb2-positive neurons in the adjacent marginal zone.

Ctip2 marks a subpopulation of layer V neurons, the corticospinal motor neurons, and plays a critical role in their develop- ment (Arlotta et al., 2005). Ctip2 is partially coexpressed with Satb1 in the perinatal cerebral cortex (Fig. 6C). In wild-type C57/ CBA, the proportion of neurons coexpressing Satb1 and Ctip2 amounted to $64 \%$ of the Satb1 + neurons and $36 \%$ of the Ctip2+ neurons at E18.5 (Fig. 6C,F), indicating that, at the difference of Satb2 (Alcamo et al., 2008; Britanova et al., 2008), Satb1 expression is compatible with high levels of Ctip2 expression. We examined whether the decrease in the number of neurons expressing Satb1 observed in $\mathrm{H}-2 \mathrm{Z} 1$ homozygous mice resulted in a change in the number of Ctip2+ neurons. The number of Ctip2+ neurons was not modified (Fig. 6D, F; 97\% of controls; $p=0.47)$. The numbers and distribution of deep-layer neurons marked with Tbr1 were not affected in homozygous C57/CBA transgenics (data not shown). Similar observations were obtained in homozygous $\mathrm{BALB} / \mathrm{c}$ transgenics at P1. It was not 
possible to obtain a reliable quantification of the number of cells expressing Ror $\beta$ transcripts due to their uneven localization in the depth of reacted sections. Nevertheless, $\operatorname{Ror} \beta$ expression was not qualitatively modified in $\mathrm{H}-2 \mathrm{Z} 1$ homozygous mutants (Fig. 5E). In conclusion, we detected no layer phenotype in pyramidal neurons of $\mathrm{H}-2 \mathrm{Z} 1$ homozygous mice upon Satb1 downregulation.

All of the cell counts described above avoided the rostral part of the cortex and were performed in the parietal cortex at an intermediate anteroposterior level corresponding to the rostral end of the hippocampus [Fig. 6G, intermediate somatosensory (IS)]. However, a relative preservation of Satb1 expression in the rostral cortex of homozygous transgenics could be indicative of an area-specific modulation of Satb1 downregulation. To examine this possibility, a landmark was required to delineate reliably the different areas in the E18.5 cortex. Lmo4 is highly expressed in the anterior and posterior aspects of the perinatal cerebral cortex and is excluded from a parietal domain that grossly corresponds to the presumptive somatosensory area. We used alternate sections stained for Lmo4 transcript to delimit four different areas: a rostrodorsal-motor area (RM) and a dorsocaudal/visual area (CV) where Lmo4 is highly expressed and rostral (RS) and intermediate (IS) components of the somatosensory area, in which Lmo4, even if highly expressed in deep cortical layers, is not present in superficial layers (Fig. 6G). In H-2Z1 homozygous mutants, the number of Satb1-expressing cells was decreased in all tested areas. We mentioned above that the number of Satb1 cells was decreased in the IS to $15 \%$ of controls. We now show that, in E18.5 homozygous H2Z1/B6 mutants, Satb1+ neurons represented 33.3 , 38.9, and $18.7 \%$ of controls in RM, RS, and CV, respectively (Fig. $6 H$ ). Thus, IS and CV were similarly affected ( $>80 \%$ decrease in the number of Satb 1 neurons), while RM and RS were comparatively less affected (65\% decrease in the number of Satb1 neurons), confirming that the rostral cortex is globally less affected by the H-2Z1 mutation than the rest of the cortex. Conversely, the severity of the Satb 1 phenotype differed between the rostral (RS, 65\%) and intermediate (IS, 80\%) subdomains of the somatosensory cortex, suggesting that the observed regional differences are not area specific. This observation strengthens the view that the area-specific regulation of expression of the $\mathrm{H}-2 \mathrm{Z} 1$ transgene and the mutation of Satb1 and Tbc1d5 induced by its insertion are distinct events.

\section{Interneuron distribution in the cerebral cortex of homozygous embryos}

In addition to pyramidal neurons, a large number of interneurons labeled for GABA or Sst or traced with the Dlx $5 / 6$ driver coexpress Satb1. To investigate the potential influence of the $\mathrm{H}-2 \mathrm{Z} 1$ transgene on the differentiation of cortical GABAergic interneurons, we compared the cortical expression of two GABAergic interneuron markers, Lhx6 and Sst, in homozygous transgenics to their wild-type littermates. Lhx6 and Sst are expressed from early stages in MGE-derived GABAergic interneurons (Taniguchi et al., 2011). In situ hybridization was used because reliable immunolabeling for Lhx6 or Sst could not be obtained in the cerebral cortex at E18.5 with available antibodies. Successive vibratome sections of wild-type (Fig. 7A, WT) and homozygous transgenics (Fig. 7A, H-2Z1/H-2Z1) were treated for the detection of Satb1, Lhx6, and Sst (Fig. 7A). As described above (Figs. $5 B, 6 B, D$ ), Satb1 expression was downregulated in E18.5 C57/CBA homozygous transgenics compared with controls. The distribution of $L h x 6$-labeled interneurons was not detectably modified in the cerebral cortex (Fig. 7A, arrowhead) or hippocampus (Fig. 7A, stars). The number and distribution of Sst + neurons were affected both in the dorsal and ventral forebrain of homozygous transgenics (Fig. 7A-C). Pallial (Fig. 7A, $B$, arrowheads) and subpallial (Fig. 7A, arrows) populations of $S s t+$ neurons were decreased and the distribution of $S s t+$ neurons in the hippocampus was altered (Fig. 7A, star).

Alterations in the number and areal and radial distribution of the Sst+ cortical interneurons population were quantified on ImageJ projections of Apotome of Sst-labeled neurons in 100$\mu \mathrm{m}$-thick Vibratome sections treated for the detection of Sst transcripts. In wild-type E18.5 embryos, the number of Sst neurons calculated in 500- $\mu \mathrm{m}$-wide cortical columns was 51 ( \pm 5$)$, $67( \pm 5)$, and $55( \pm 4)$ for the RM, RS, and CV, respectively. In homozygous $\mathrm{H}-2 \mathrm{Z} 1$ mutants, the density was decreased to 30 ( \pm 3$), 46( \pm 5)$, and $36( \pm 2)$ and amounted 58.5, 68.4 , and 66.7\% of the wild-type values for RM, RS, and CV, respectively. The radial distribution of Sst + neurons was also affected. In the wildtype cerebral cortex at E18.5, Sst + neurons migrate in two rows: a major row in the IZ (Fig. $7 B$, arrowheads) and a smaller contingent in the MZ. Some Sst+ neurons accumulate below the cortical plate $(\mathrm{CP})$ where they begin to enter (Fig. $7 B$ ). In homozygous transgenics, the IZ migration was sparse (Fig. $7 B$, arrowheads) and an increased proportion of $S s t+$ neurons were located in the CP (Fig. 7, compare WT and $\mathrm{H}-2 \mathrm{Z1} / \mathrm{H}-2 \mathrm{Z} 1$ in $B$, $C)$. To quantify the radial distribution of the Sst + cortical interneurons, the cortex was subdivided into three bins. The proportion of Sst neurons located in the pial superficial bin was increased in mutants in all areas examined (HH\%/WT\%: 35.10/ $14.63 \%, 27.49 / 13.74 \%$, and $24.78 / 15.52 \%$, in RM, RS, and CV, respectively).

These observations indicate that insertion of the $\mathrm{H}-2 \mathrm{Z} 1$ transgene affects the differentiation of a subtype of cortical interneurons and that the decrease in Sst + expression in cortical interneurons parallels that of Satb1.

\section{Origin of the cortical Sst interneuron phenotype in homozygous $\mathrm{H}-2 \mathrm{Z1}$ transgenics}

Because Satb1 and Sst are coexpressed in cortical interneurons, the decrease in the number of Sst+ cortical interneurons observed in homozygous $\mathrm{H}-2 \mathrm{Z} 1$ transgenics was suggestive of a regulation of Sst expression or Sst + interneuron differentiation by Satb1. Several aspects of the phenotype of homozygous transgenics - altered distribution of the remaining Sst + neurons in the cortex and hippocampus, decrease of the subpallial population of Sst + neurons-were, however, not self-evident in this context. Sst expression or cortical interneuron differentiation could be controlled by regulatory sequences located near the $\mathrm{H}-2 \mathrm{Z1}$ insertion site or rely on Tbc1d5 whose expression is downregulated in $\mathrm{H}-2 \mathrm{Z} 1$ homozygous. The Sst gene is located on chromosome 16, which makes a direct effect of $\mathrm{H}-2 \mathrm{Z} 1$ on Sst expression unlikely. Tbc1d5 is not expressed in the subpallium (Fig. 5D). We compared Tbcld5 and Satb1 expressions in the cerebral cortex of wild-type E18.5 embryos. Although their maximum expressions were somewhat out of phase, Tbcld5 and Satb1 were largely coexpressed (Fig. 7D). In contrast, we could not detect coexpression of Tbc1d5 with GABA (Fig. 7E) whereas Satb1/GABA (Fig. 7E, white dots) and Satb1/Tbc1d5 (Fig. 7E, white stars) coexpressions were readily detectable on the same preparation (Fig. 7E). Even if the combination of NBT/BCIP with immunofluorescence is not optimal, this observation suggests that downregulation of Satb1 rather than Tbcld5 is involved in the Sst phenotype of $\mathrm{H}-2 \mathrm{Z} 1$ homozygotes. 

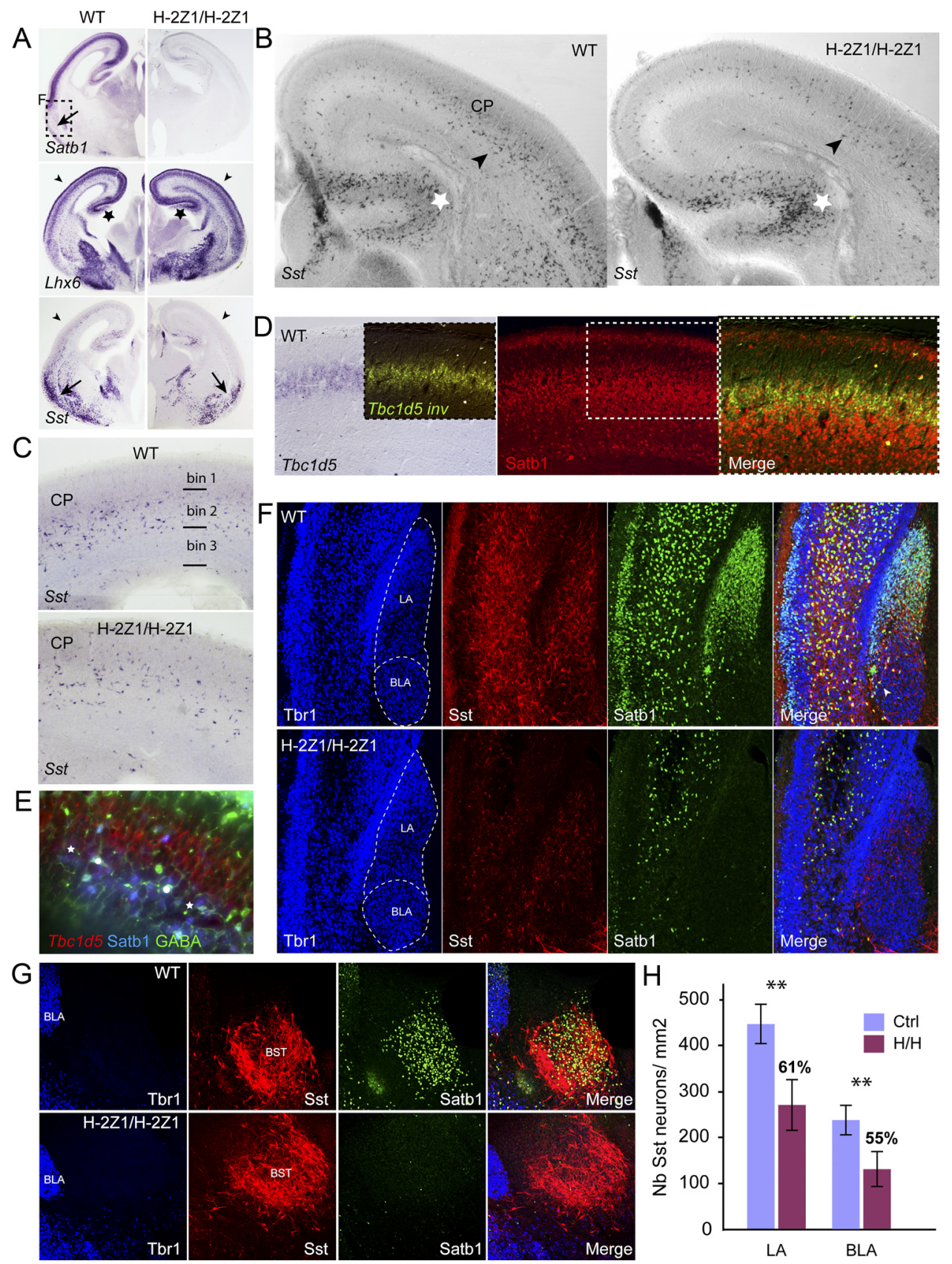

Figure 7. Abnormal development of a subset of GABAergic interneurons in homozygous $\mathrm{H}-2 Z 1$ transgenics. $A$, Successive coronal sections through the forebrain of WT and H-2Z1/H-2Z1 C57/CBA E18.5 embryos treated for the detection of Satb1, Lhx6, and Sst (somatostatin neuropeptide) transcripts. Expression of Satb1 is downregulated in homozygous transgenics, Lhx6 expression is not grossly affected. Sst labeling is decreased both in the basal forebrain (arrows) and in the cerebral cortex (arrowhead) of homozygous mutants compared with wild type. The distribution of Sst+ neurons in altered in the hippocampus (stars). $\boldsymbol{B}, \boldsymbol{C}$, Higher magnification of Sst-labeled sections (more anterior than in $\boldsymbol{A}$ ) through the cortex of wild-type and homozygous transgenics. The IZ migration of Sst + neurons is sparser in mutant than in wild type $(\boldsymbol{B}$, arrows). In addition, Sst + neurons prematurely enter the cortical plate $(\boldsymbol{B}, \boldsymbol{C},(\mathrm{C})$ in mutants. To quantify this phenotype, the cortex was subdivided into three bins (bins 1-3). D, Section through the cerebral cortex of E18.5 wild-type embryo double stained for Tbc1d5 transcripts in blue (NBT/BCIP) and Satb1 immunofluorescence (red). A negative image of the in situ was obtained with Photoshop resulting in a green dark-field contrast. The $T b c 1 d 5$ and Satb1 pictures were merged (area outlined in D). Tbc $1 d 5$ and Satb1 are largely coexpressed. $\boldsymbol{E}$, Similar section treated for the detection of $T b c 1 d 5$ transcripts (red), Satb1 immunofluorescence (blue), and GABA immunofluorescence (green). The white dots and white stars mark Satb1/GABA and Satb1/Tbc1dc double-labeled cells, respectively. $F, G$, Consequence of $\mathrm{H}$-2Z1 insertion on the expression of Sst in the amygdala. Sections through wild-type and H-2Z1 homozygous E18.5 brains immunostained for Tbr1 (blue), Sst (red), and Satb1 (green). The subpallium region illustrated is outlined in $\boldsymbol{A}$, WT-Satb1. The red channel (Sst) in the four pictures was acquired with the same confocal settings. $\boldsymbol{F}$, The LA contains a large population of Satb1+/Sst + neurons, while the BLA contains few Sst +/Satb1+ neurons. They were delineated in the blue channel (Tbr1). Notice the general decrease in the intensity of Sst staining in H-2Z1/H-2Z1. G, On the same section, the BST expresses strongly Satb1 and Sst in complementary patterns. Sst staining of is not modified in the BST of mutants. $\boldsymbol{H}$, Cell counts indicate that the number of Sst + neurons is reduced by $>50 \%$ in both LA and BLA nuclei in H-2Z1/H-2Z1 embryos. ${ }^{* *} p<0.05$. Error bars indicate SEM.

In this context, the decrease observed in an Sst + population of the subpallium was unexpected. Satb1 transcripts were indeed detected in the neuroepithelium of the ganglionic eminences at E14.5, but the timing was slightly too late and no immunoreactive protein could be detected in the neuroepithelium at this stage. A more careful examination of the subpallium indicated that Satb1 is expressed in restricted subpopulations of Sst + neurons in several amygdalar nuclei. 


\section{Sst neuron distribution in the amygdalar complex of homozygous embryos}

The basal forebrain of perinatal embryos contains a large population of Sst-immunoreactive interneurons. Three amygdalar nuclei, the LA, the BLA, and the amygdalar portion of the BST, were chosen for the analysis of the fate of Sst + neurons in the basal forebrain of H-2Z1 homozygous mutants. Virtually all of the densely packed neurons of the LA are Satb1 immunoreactive, whereas the adjacent BLA contains a discrete population of scattered Satb1+ neurons (Fig. 7F, WT, Satb1). The BST appears as a well delimited group of intensely Satb1-immunoreactive nuclei (Fig. 7G, WT, Satb1). Satb1/Sst coexpression was quantified in the LA, BLA, and BST. We could not reliably detect Satb1negative Sst + neurons in the LA. All the Sst + neurons of the LA were considered Satb1 + . In the BLA, $89.6 \pm 3.3 \%$ of the Sst + neurons coexpressed Satb1. In contrast, only $2.1 \%$ of the Sst+ neurons of the BST coexpressed Satb1.

In $\mathrm{H}-2 \mathrm{Z} 1$ homozygous transgenics, the decrease in Satb1 expression was accompanied by a marked decrease in the global intensity of Sst immunoreactivity in the LA and BLA as well as in the adjacent pyriform cortex (Fig. 7F, compare Sst expression in WT and $\mathrm{H}-2 \mathrm{Z1} / \mathrm{H}-2 \mathrm{Z} 1$ under the same confocal acquisition settings). In contrast, on the same sections, the intensity of Sst labeling was not affected in the BST of $\mathrm{H}-2 \mathrm{Z} 1 / \mathrm{H}-2 \mathrm{Z} 1$ mutants despite a complete disappearance of Satb1+ neurons (Fig. 7G). To quantify the distribution of Sst + neurons in mutant and wild-type, the areal density of Sst neurons in the LA and BLA was quantified on sections of pairs of E18.5 H-2Z1 homozygous mutants and wildtype littermates. The number of Sst + neurons was decreased to $60.6 \%(p=0.014)$ of wild-type value in the LA and to $55 \%(p=$ 0.27 ) in the BLA (Fig. $7 H$ ). Interestingly, in the mutant BLA, $56.7 \%$ of the Sst + neurons still coexpressed Satb1. The number of Sst+ neurons in the BST was not detectably modified.

Together, given that Tbcld5 is not detectably expressed in the subpallium, these observations indicate that Satb1 is likely to control Sst expression in several neuronal populations of the subpallium and cerebral cortex.

\section{Discussion}

The present study partially confirmed our hypothesis that $\mathrm{H}-2 \mathrm{Z} 1$ reports the expression of adjacent somatosensory cortexexpressed genes. $\mathrm{H}-2 \mathrm{Z} 1$ is inserted in the regulatory landscape of Satb1 and Tbcld5, two genes highly expressed in the developing somatosensory cortex, and reports for a subdomain of their expression profiles. In addition, interaction of $\mathrm{H}-2 \mathrm{Z1}$, which contains its own regulatory sequences, with genomic sequences located at the transgene insertion site produced very interesting complexities, which are discussed below. We also found that the $\mathrm{H}-2 \mathrm{Z} 1$ mutation interferes with the differentiation of several populations of neurons in the cerebral cortex and amygdala, which is likely to result from $S a t b 1$ downregulation.

\section{$\mathrm{H}-2 \mathrm{Z} 1$ transgene behavior is influenced by genetic modifiers}

Gene expression as well as the severity of mutations and/or diseases can be dramatically altered by the activity of genetic modifiers (Liu and Yan, 2007; Yan and Liu, 2010; Kearney, 2011). The $\mathrm{H}-2 \mathrm{Z} 1$ transgene is sensitive to genetic background-dependent modifiers in two ways. First, cortical area and layer expression of $\mathrm{H}-2 \mathrm{Z} 1$ was altered by changing the genetic background and also depended on the transgene and/or modifiers parental inheritance. Modified H-2Z1 expression was more intense and included the originally described somatosensory area-specific expression pattern, suggesting that modifiers may act on the level of transgene expression. The enhancer trap behavior of the $\mathrm{H}-2 \mathrm{Z1}$ transgene is in part mediated by DNA methylation (Cohen-Tannoudji et al., 2000). It is therefore possible that changing genetic background results in epigenetic regulation, as previously reported (Allen et al., 1990; Daxinger and Whitelaw, 2010). Genetic background-dependent modifiers also control the lethality of homozygous transgenics on a C57/CBA genetic background, whereas homozygous BALB/c mice survive to adulthood. Dependence on genetic background of mouse mutant phenotypes has been previously reported. The severity of craniofacial defects in Otx2 heterozygous mutant mice ranged from acephaly in a C57BL/6 background to absence of detectable defects in CBA background (Hide et al., 2002). Similarly, lethality phenotype of EGF receptor mutation is highly dependent on genetic background, mutant embryos dying shortly after implantation in a CF-1 background, while mutant mice survived to 3 weeks after birth in a CD-1 background (Threadgill et al., 1995). It is unclear whether the lethality of C57/CBA homozygous $\mathrm{H}-2 \mathrm{Z} 1$ mice is a consequence of $S a t b 1$ or Tbc1d5 downregulation or results from other long-distance interferences induced by insertion of the transgene. Satb1 $1^{-1-}$ mutants have been described to survive birth and to die at $\sim 3$ weeks of age (Alvarez et al., 2000). Although no effect of the genetic background on the time of death has been reported, the variable hypotrophy of the Satb1 $1^{-1-}$ mice was attributed to the mixed C57BL/6 and 129/Ola genetic background (Alvarez et al., 2000).

\section{Interplay between the $\mathrm{H}-2 \mathrm{Z} 1$ transgene and flanking genomic sequences}

$\mathrm{H}-2 \mathrm{Zl}$ integrated in a large intergenic region on chromosome 17, 100 and $460 \mathrm{~kb}$ away from the first proximal and distal flanking genes. Several mouse genes have been shown to rely on enhancers localized hundreds of kilobases away from their promoter, and a recent study suggests that such long-range gene regulation is frequent (Lettice et al., 2003; Ruf et al., 2011). Interestingly, four of the five genes found in a $1 \mathrm{Mb}$ interval around $\mathrm{H}-2 \mathrm{Z1}$ insertion site were expressed in the somatosensory cortex during the first postnatal week, suggesting that the transgene has landed in a broad regulatory domain acting on several transcription units. Expression of the $\mathrm{H}-2 \mathrm{Z} 1$ flanking genes is clearly broader than that of H-2Z1 itself especially on the C57/CBA genetic background. Satb1 expression is turned on in the cortex at E14.5, whereas $\mathrm{H}-2 \mathrm{Z} 1$ expression is turned on by $\mathrm{P} 2$ (Cohen-Tannoudji et al., 1994). H-2Z1 therefore reports a subset of the postnatal expression domains of the flanking genes especially in the case of Satb1. However, at the cellular level, coexpression of $\mathrm{H}-2 \mathrm{Z1}$ transgene with Satb1 was limited. We previously reported that H-2Z1 does not colocalize with Gad-67 transcripts or with the calcium binding proteins parvalbumin and calretinin in the cerebral cortex of P7 C57/CBA transgenics (Gitton et al., 1999a). In contrast, we find here that Satb1 is expressed in a subpopulation of cortical GABAergic interneurons, confirming the limited overlap between Satb1- and H-2Z1-positive cells. It seems therefore that regulatory sequences trapped by the $\mathrm{H}-2 \mathrm{Z1}$ transgene impinge on regional rather than cell type-specific gene expression. Transgene insertion affected the cortical expression of the closest flanking genes, Satb1 and Tbc1d5, probably by interacting with regulatory elements and preventing their interactions with the promoters of flanking genes. Expression of Satb1 and Tbc1d5 was also affected in cells where $\mathrm{H}-2 \mathrm{Z} 1$ is not expressed, suggesting that the control of lac $Z$ expression and the interference with flanking genes expression involve distinct mechanisms. 
Finally, it should be noted that the $\mathrm{H}-2 \mathrm{Z} 1$ transgene contains $2 \mathrm{~kb}$ of $5^{\prime}$ genomic sequences from the $\mathrm{H}-2 \mathrm{~K}^{\mathrm{b}}$ gene including various regulatory elements (Cohen-Tannoudji et al., 1992). Therefore, the specific somatosensory expression of $\mathrm{H}-2 \mathrm{Z1}$ C57/ CBA may result from the interplay between $\mathrm{H}-2 \mathrm{~K}^{\mathrm{b}}$ upstream region and Satb1 regulatory modules. On top of that, modulation of transgene expression by genetic modifiers unraveled by this study and by Gitton et al. (1999a) may also participate in the establishment of the unique cortical expression profile of the $\mathrm{H}-2 \mathrm{Z} 1$ transgenic line. Interestingly, two recently published transgenic lines exhibit somatosensory area-specific expression (Lazutkin et al., 2007; Liao and $\mathrm{Xu}$, 2008). In these lines as in the $\mathrm{H}-2 \mathrm{Z} 1$ transgenics, area-specific expression is likely to result from position effects.

\section{Cortical layer-type neurons develop normally in homozygous H-2Z1 transgenics}

Despite an $86 \%$ decrease in the number of neurons expressing Satb1, we could not detect a layer type specification phenotype in the cerebral cortex of $\mathrm{H}-2 \mathrm{Z} 1$ homozygous mice. Ctip2 is involved in the generation of layer $\mathrm{V}$ subcortical projection neurons (Chen et al., 2005; Molyneaux et al., 2005). In wild-type E18.5 embryo, $36 \%$ of the Ctip2+ neurons coexpress Satb1 compared with $<5 \%$ that coexpress the Satb1 closely related Satb2 chromatin modifier (Alcamo et al., 2008). Thus, Satb1 expression does not result in Ctip2 downregulation. In contrast, Satb2 controls upper-layer cortical neuron specification (Alcamo et al., 2008; Britanova et al., 2008) through repression of Ctip2 expression. Our observations indicate that depletion of Satb1 or Satb2 has distinct consequences for cortical development. These observations are consistent with a recent study that detected no layer phenotype in Satb1 KO (Balamotis et al., 2012).

\section{Alteration of a population of Sst-expressing neurons in homozygous transgenics: a consequence of Satb 1 downregulation?}

Our data suggest that Sst expression is controlled by a cellautonomous function of Satb1 in several subpopulations of Sst+ neurons of the cerebral cortex and subpallium. The observed depletion in Sst + neurons is not likely to result from a direct influence of $\mathrm{H}-2 \mathrm{Z} 1$ insertion or other $\mathrm{H}-2 \mathrm{Z} 1$ flanking genes: $\mathrm{H}-2 \mathrm{Z} 1$ is inserted in Chr17, while Sst is located on Chr16; Tbc1d5 is not expressed in the subpallium or in GABAergic neurons; expression of the Btg3 and Plcl2 genes is not detectably modified in $\mathrm{H}-2 \mathrm{Z1}$ homozygous transgenics.

However, in homozygous transgenics, a second phenotype is observed in the remaining $S s t+$ neurons whose layer distribution is affected in the cerebral cortex and the hippocampus. While a cell-autonomous function of Satb1 could control cytoskeletal reorganization or the interpretation of local cues by Sst + interneurons, a modification of the environment in homozygous transgenics cannot be ruled out. Both Satb1 and Tbcld5 are broadly expressed in pyramidal neurons known to be involved in the layer-specific attraction of distinct populations of GABAergic interneurons (Lodato et al., 2011). Interestingly, among the Satb1 targets found to be downregulated in the cerebral cortex of Satb1 KO (Balamotis et al., 2012), three (Arc, Thbsl, and BdnF) could affect neuronal migration either cell autonomously or nonautonomously. Downregulation of the activity-regulated cytoskeletal-associated protein (Arc), for example, could affect migration cell-autonomously. Thrombospondin 1 (Thbs1) is present in the SVZ and acts as a physiological ligand of ApoER2 and VLDLR (very low-density lipoprotein receptor) (Blake et al.,
2008). In the absence or decrease of Thbs1 in the SVZ, the Sst+ cortical interneurons could respond to the superficially expressed alternative ligand Reelin resulting in a more superficial distribution. This speculative scenario illustrates how modification of attractive or repulsive cues upon Satb1 or Tbc1d5 downregulation could modify the distribution of Sst + cortical and hippocampal interneurons. In this respect, it would be interesting to compare the $\mathrm{H}-2 \mathrm{Z} 1$ phenotype of Sst+ neurons with that of Satb $1^{-1-}$ and with the conditional knock out of Satb 1 in GABAergic interneurons.

In conclusion, we show that $\mathrm{H}-2 \mathrm{Zl}$ is inserted in regulatory sequences controlling the expression of the two adjacent genes Satbl and Tbcld5, in particular in the developing cerebral cortex. The somatosensory-specific expression of $\mathrm{H}-2 \mathrm{Z1}$ in C57/CBA transgenics does not solely depend on regulatory elements at its insertion site but is also shaped by genetic background associated modifier genes. The differentiation of several Sst + neuronal populations in the cerebral cortex and amygdala was impaired in homozygous transgenics. We provide arguments suggesting that this phenotype results from the downregulation of Satb1, which is expressed in these neurons.

\section{References}

Alcamo EA, Chirivella L, Dautzenberg M, Dobreva G, Fariñas I, Grosschedl R, McConnell SK (2008) Satb2 regulates callosal projection neuron identity in the developing cerebral cortex. Neuron 57:364-377.

Allen ND, Norris ML, Surani MA (1990) Epigenetic control of transgene expression and imprinting by genotype-specific modifiers. Cell 61:853-861.

Alvarez JD, Yasui DH, Niida H, Joh T, Loh DY, Kohwi-Shigematsu T (2000) The MAR-binding protein SATB1 orchestrates temporal and spatial expression of multiple genes during T-cell development. Genes Dev 14:521-535.

Arlotta P, Molyneaux BJ, Chen J, Inoue J, Kominami R, Macklis JD (2005) Neuronal subtype-specific genes that control corticospinal motor neuron development in vivo. Neuron 45:207-221.

Balamotis MA, Tamberg N, Woo YJ, Li J, Davy B, Kohwi-Shigematsu T, Kohwi Y (2012) Satb1 ablation alters temporal expression of immediate early genes and reduces dendritic spine density during postnatal brain development. Mol Cell Biol 32:333-347.

Bally-Cuif L, Wassef M (1994) Ectopic induction and reorganization of Wnt-1 expression in quail/chick chimeras. Development 120:3379-3394.

Blake SM, Strasser V, Andrade N, Duit S, Hofbauer R, Schneider WJ, Nimpf J (2008) Thrombospondin-1 binds to ApoER2 and VLDL receptor and functions in postnatal neuronal migration. EMBO J 27:3069-3080.

Briscoe J, Pierani A, Jessell TM, Ericson J (2000) A homeodomain protein code specifies progenitor cell identity and neuronal fate in the ventral neural tube. Cell 101:435-445.

Britanova O, de Juan Romero C, Cheung A, Kwan KY, Schwark M, Gyorgy A, Vogel T, Akopov S, Mitkovski M, Agoston D, Sestan N, Molnár Z, Tarabykin V (2008) Satb2 is a postmitotic determinant for upper-layer neuron specification in the neocortex. Neuron 57:378-392.

Brodmann K (1909) Vergleichende Lokalisationslehre der Grosshirnrinde in ihren Prinzipien dargestellt auf Grund des Zellenbaues von Dr. K. Brodmann. Leipzig: J. A. Barth.

Cai S, Han HJ, Kohwi-Shigematsu T (2003) Tissue-specific nuclear architecture and gene expression regulated by SATB1. Nat Genet 34:42-51.

Chen B, Schaevitz LR, McConnell SK (2005) Fezl regulates the differentiation and axon targeting of layer 5 subcortical projection neurons in cerebral cortex. Proc Natl Acad Sci U S A 102:17184-17189.

Cohen-Tannoudji M, Morello D, Babinet C (1992) Unexpected positiondependent expression of $\mathrm{H}-2$ and beta 2-microglobulin/lacZ transgenes. Mol Reprod Dev 33:149-159.

Cohen-Tannoudji M, Babinet C, Wassef M (1994) Early determination of a mouse somatosensory cortex marker. Nature 368:460-463.

Cohen-Tannoudji M, Vandormael-Pournin S, Drezen J, Mercier P, Babinet C, Morello D (2000) lacZ sequences prevent regulated expression of housekeeping genes. Mech Dev 90:29-39.

Cooke HJ, Lee M, Kerr S, Ruggiu M (1996) A murine homologue of the 
human DAZ gene is autosomal and expressed only in male and female gonads. Hum Mol Genet 5:513-516.

Daxinger L, Whitelaw E (2010) Transgenerational epigenetic inheritance: more questions than answers. Genome Res 20:1623-1628.

Dickinson LA, Joh T, Kohwi Y, Kohwi-Shigematsu T (1992) A tissuespecific MAR/SAR DNA-binding protein with unusual binding site recognition. Cell 70:631-645.

Gitton Y, Cohen-Tannoudji M, Wassef M (1999a) Specification of somatosensory area identity in cortical explants. J Neurosci 19:4889-4898.

Gitton Y, Cohen-Tannoudji M, Wassef M (1999b) Role of thalamic axons in the expression of $\mathrm{H}-2 \mathrm{Z1}$, a mouse somatosensory cortex specific marker. Cereb Cortex 9:611-620.

Hide T, Hatakeyama J, Kimura-Yoshida C, Tian E, Takeda N, Ushio Y, Shiroishi T, Aizawa S, Matsuo I (2002) Genetic modifiers of otocephalic phenotypes in Otx2 heterozygous mutant mice. Development 129:4347-4357.

Ishibashi K, Kanno E, Itoh T, Fukuda M (2009) Identification and characterization of a novel Tre-2/Bub2/Cdc16 (TBC) protein that possesses Rab3A-GAP activity. Genes Cells 14:41-52.

Joshi PS, Molyneaux BJ, Feng L, Xie X, Macklis JD, Gan L (2008) Bhlhb5 regulates the postmitotic acquisition of area identities in layers II-V of the developing neocortex. Neuron 60:258-272.

Kearney JA (2011) Genetic modifiers of neurological disease. Curr Opin Genet Dev 21:349-353.

Lavenu A, Roland J, Poirier C, Cazenave P, Babinet C, Morello D (1996) Genomic structure and precise mapping of a thymic regulatory region on mouse chromosome 17 revealed by a c-myc transgene insertion. Genomics 34:381-388.

Lazutkin AA, Meyer BI, Anokhin KV (2007) Transgene 6A-99 is a molecular marker of developing somatosensory cortex in mice (in Russian). Ontogenez 38:21-32.

Lebrand C, Cases O, Wehrlé R, Blakely RD, Edwards RH, Gaspar P (1998) Transient developmental expression of monoamine transporters in the rodent forebrain. J Comp Neurol 401:506-524.

Lettice LA, Heaney SJ, Purdie LA, Li L, de Beer P, Oostra BA, Goode D, Elgar G, Hill RE, de Graaff E (2003) A long-range Shh enhancer regulates expression in the developing limb and fin and is associated with preaxial polydactyly. Hum Mol Genet 12:1725-1735.

Liao GY, Xu B (2008) Cre recombinase-mediated gene deletion in layer 4 of murine sensory cortical areas. Genesis 46:289-293.

Liu XZ, Yan D (2007) Ageing and hearing loss. J Pathol 211:188-197.

Lodato S, Rouaux C, Quast KB, Jantrachotechatchawan C, Studer M, Hensch TK, Arlotta P (2011) Excitatory projection neuron subtypes control the distribution of local inhibitory interneurons in the cerebral cortex. Neuron 69:763-779.

Louvi A, Alexandre P, Métin C, Wurst W, Wassef M (2003) The isthmic neuroepithelium is essential for cerebellar midline fusion. Development 130:5319-5330.

Matsuda Y, Harada YN, Natsuume-Sakai S, Lee K, Shiomi T, Chapman VM (1992) Location of the mouse complement factor $\mathrm{H}$ gene (cfh) by FISH analysis and replication R-banding. Cytogenet Cell Genet 61:282-285.
Molyneaux BJ, Arlotta P, Hirata T, Hibi M, Macklis JD (2005) Fezl is required for the birth and specification of corticospinal motor neurons. Neuron 47:817-831.

O'Leary DD, Chou SJ, Sahara S (2007) Area patterning of the mammalian cortex. Neuron 56:252-269.

Paysan J, Kossel A, Bolz J, Fritschy JM (1997) Area-specific regulation of $\gamma$-aminobutyric acid type A receptor subtypes by thalamic afferents in developing rat neocortex. Proc Natl Acad Sci U S A 94:6995-7000.

Pinkel D, Gray JW, Trask B, van den Engh G, Fuscoe J, van Dekken H (1986) Cytogenetic analysis by in situ hybridization with fluorescently labeled nucleic acid probes. Cold Spring Harb Symp Quant Biol 51:151-157.

Rash BG, Grove EA (2006) Area and layer patterning in the developing cerebral cortex. Curr Opin Neurobiol 16:25-34.

Ruf S, Symmons O, Uslu VV, Dolle D, Hot C, Ettwiller L, Spitz F (2011) Large-scale analysis of the regulatory architecture of the mouse genome with a transposon-associated sensor. Nat Genet 43:379-386.

Seaman MN, Harbour ME, Tattersall D, Read E, Bright N (2009) Membrane recruitment of the cargo-selective retromer subcomplex is catalysed by the small GTPase Rab7 and inhibited by the Rab-GAP TBC1D5. J Cell Sci 122:2371-2382.

Shimogori T, Banuchi V, Ng HY, Strauss JB, Grove EA (2004) Embryonic signaling centers expressing BMP, WNT and FGF proteins interact to pattern the cerebral cortex. Development 131:5639-5647.

Takenaka K, Fukami K, Otsuki M, Nakamura Y, Kataoka Y, Wada M, Tsuji K, Nishikawa S, Yoshida N, Takenawa T (2003) Role of phospholipase C-L2, a novel phospholipase C-like protein that lacks lipase activity, in B-cell receptor signaling. Mol Cell Biol 23:7329-7338.

Takeuchi A, Hamasaki T, Litwack ED, O'Leary DD (2007) Novel IgCAM, MDGA1, expressed in unique cortical area- and layer-specific patterns and transiently by distinct forebrain populations of Cajal-Retzius neurons. Cereb Cortex 17:1531-1541.

Taniguchi H, He M, Wu P, Kim S, Paik R, Sugino K, Kvitsani D, Fu Y, Lu J, Lin Y, Miyoshi G, Shima Y, Fishell G, Nelson SB, Huang ZJ (2011) A resource of Cre driver lines for genetic targeting of GABAergic neurons in cerebral cortex. Neuron 71:995-1013.

Threadgill DW, Dlugosz AA, Hansen LA, Tennenbaum T, Lichti U, Yee D, LaMantia C, Mourton T, Herrup K, Harris RC (1995) Targeted disruption of mouse EGF receptor: effect of genetic background on mutant phenotype. Science 269:230-234.

Yan D, Liu XZ (2010) Modifiers of hearing impairment in humans and mice. Curr Genomics 11:269-278.

Yoneda M, Suzuki T, Nakamura T, Ajima R, Yoshida Y, Kakuta S, Katsuko S, Iwakura Y, Shibutani M, Mitsumori K, Yokota J, Yamamoto T (2009) Deficiency of antiproliferative family protein Ana correlates with development of lung adenocarcinoma. Cancer Sci 100:225-232.

Yoshida Y, Matsuda S, Ikematsu N, Kawamura-Tsuzuku J, Inazawa J, Umemori H, Yamamoto T (1998) ANA, a novel member of Tob/BTG1 family, is expressed in the ventricular zone of the developing central nervous system. Oncogene 16:2687-2693. 